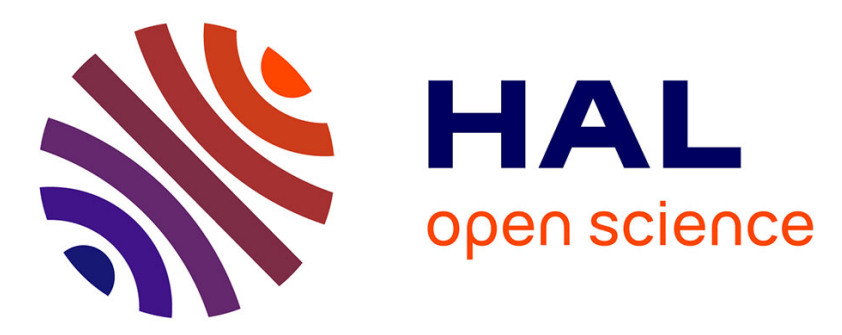

\title{
Molecular dynamics simulation of ballistic effects in simplified nuclear waste glasses
}

\author{
Amreen Jan, Jean-Marc Delaye, S. Gin, Sebastien Kerisit
}

\section{To cite this version:}

Amreen Jan, Jean-Marc Delaye, S. Gin, Sebastien Kerisit. Molecular dynamics simulation of ballistic effects in simplified nuclear waste glasses. Journal of Non-Crystalline Solids, 2019, 505, pp.188-201. 10.1016/j.jnoncrysol.2018.11.021 . cea-02510729

\section{HAL Id: cea-02510729 https://hal-cea.archives-ouvertes.fr/cea-02510729}

Submitted on 18 Mar 2020

HAL is a multi-disciplinary open access archive for the deposit and dissemination of scientific research documents, whether they are published or not. The documents may come from teaching and research institutions in France or abroad, or from public or private research centers.
L'archive ouverte pluridisciplinaire HAL, est destinée au dépôt et à la diffusion de documents scientifiques de niveau recherche, publiés ou non, émanant des établissements d'enseignement et de recherche français ou étrangers, des laboratoires publics ou privés. 


\title{
Molecular dynamics simulation of ballistic effects in simplified nuclear waste glasses
}

\author{
Amreen Jan ${ }^{1,2}$, Jean-Marc Delaye ${ }^{1}$, Stéphane Gin $^{1}$, Sebastien Kerisit ${ }^{2}$ \\ ${ }^{1}$ CEA, DEN, Service d'études de vitrification et procédés hautes températures, 30207 \\ Bagnols-sur-Cèze, France \\ ${ }^{2}$ Physical Sciences Division, Pacific Northwest National Laboratory, Richland, Washington \\ 99352, United States
}

\begin{abstract}
Ballistic effects in simple sodium borosilicate $\left(\frac{\mathrm{Na}_{2} \mathrm{O}}{\mathrm{B}_{2} \mathrm{O}_{3}}=1\right)$ and sodium alumino-borosilicate glasses $\left(\frac{\mathrm{Na}_{2} \mathrm{O}-\mathrm{Al}_{2} \mathrm{O}_{3}}{\mathrm{~B}_{2} \mathrm{O}_{3}}=1\right)$ were investigated using molecular dynamics simulations. Specifically, the glasses were irradiated with heavy projectiles that caused atomic displacements by elastic collisions (displacement cascades) and progressively damaged the bulk glass. The accumulated pressure and internal energy inside the glass were found to saturate with deposited energy. Furthermore, structural analysis of the irradiated glasses revealed several important ballistic effects including a decrease in glass density, depolymerization of the borosilicate network, and increase in chemical mixing, short range and intermediate disorder. The magnitude of radiation damage was found to depend on the glass composition and, in general, alumino-borosilicate glasses were found to be slightly less damaged, after irradiation, as compared to borosilicate glasses.
\end{abstract}

\section{Keywords}

Molecular dynamics, borosilicate glasses, ballistic effects

\section{Introduction}

Immobilization of High Level Waste (HLW) in borosilicate matrices and further disposal into geological repository has been regarded as one of the best ways for long-term isolation of HLW from the biosphere [1,2]. To confine radionuclides (RN), a glass must present a high physical and chemical durability. Under repository conditions, RN are expected to stay confined until the glass matrix has been reached by groundwater and begins to corrode [3]. Consequently, glass corrosion has been studied extensively, focusing primarily on the effects of environmental conditions ( $\mathrm{pH}$, temperature, glass-surface-to-solution-volume ratio) and glass compositions, and different regimes of alteration have been identified (initial alteration rate, residual rate, and resumption rate [4,5]) . Today, it is widely accepted that the alteration layer that forms between the pristine glass and the solution is responsible for the alteration rate drop [6-8]. But the glass corrosion behavior, and thus glass durability, may be affected by internal emission of radiation particles $(\alpha, \beta$, and $\gamma)$. 
Various studies have been conducted to determine the effects of each type of radiation on the structure of unaltered glasses using doping techniques $(\mathrm{Cm}, \mathrm{Pu})$, external irradiation beams, and atomistic modeling (for ballistic collisions only) [9-13]. Due to their long half-lives, $\alpha$ radionuclides are expected to dominate the long-term contribution to the deposited energy [14] and, indeed, a study of nuclear waste glasses subjected to different irradiation fluxes showed that recoil nuclei produced during $\alpha$-decay were the main source of irradiation damage [15]. The nuclear collisions (or ballistic collisions) lead to swelling, a decrease of hardness, an increase in fracture toughness, and an increase in structural disorder and depolymerization [15].

The extent by which radiation can affect glass corrosion, however, is still controversial. Earlier studies conducted on the impact of radiation $(\alpha, \beta$, and $\gamma)$ reported no significant impact on glass alteration kinetics (both initial and residual rates) [16-21]. In contrast, recent experiments conducted by Mougnaud et al. [22] in residual rate regime, using multiple energy gold ion irradiation with dominant nuclear dose( 200MGy), showed a significant increase of the alteration rate and thickness of the alteration layer in pre-irradiated glasses compared to non-irradiated glasses. In fact, changes in the residual rate and the alteration layer thickness appeared to attain saturation around the same deposited dose, and thus showed a behavior akin to that described above for structural properties. Therefore, it remains unclear to what extent radiation damage to the pristine glass structure can impact corrosion. In particular, the correlation between the alteration layer structure and the initial glass structure remains an open question.

The present work is the first part of an ongoing study aimed at addressing this question using atomistic modeling techniques, namely, classical molecular dynamics (MD) and Monte Carlo (MC) methods [23-25]. Here, series of pristine and irradiated sodium borosilicate (SBN) and sodium alumino-borosilicate (SBNA) glasses were simulated using MD and a systematic analysis of radiation effects was performed to correlate structural changes induced by the ballistic effects to glass chemical composition. In the second part of this study, which will be the subject of a future publication, the structural changes will be implemented in a Monte Carlo code to investigate their effects on glass corrosion.

MD simulations have proved to be a powerful tool for understanding ballistic damage induced by recoil nuclei in glasses, particularly the changes in short- and medium-range order[26,27] $[27,28]$. Density evolution with deposited dose using MD followed similar trends as measured for curium-doped and externally-irradiated glasses. In fact, stabilization of glass swelling around same dose $\left(10^{21} \mathrm{keV} \cdot \mathrm{cm}^{-3}\right)$ bolstered the idea that network modifications are a consequence of damage induced by recoil nuclei [11]. Furthermore, correlation of microstructural parameters (increase in disorder and depolymerization) and experimental results has led to the "ballistic disordering fast quenching model". In this model, displacement cascades (DC) generated by the recoil nucleus create significant structural disorder and also raise the local temperature and, since the bulk of the glass is at ambient temperature, it quickly quenches from high fictive temperature. This occurs at very short time scales $\left(10^{-12} \mathrm{~s}\right)$ and the glass is thus not able to reach an equilibrium state and freezes at higher enthalpy [2831].

Reliable interatomic potentials are critical to an accurate description of the structure and properties of pristine and irradiated glasses. In particular, a limited number of potentials are available for SBN and SBNA glasses due to the difficulties in simulating accurately the nonlinear dependence of boron coordination on composition[32,33]. The correct reproduction of boron coordination is an important criterion to consider while developing new potentials. A few years ago, Kieu et al.[34] developed a set of composition-dependent potentials for SBN glasses by fitting parameters based on Dell and Bray model [32,35]. Even though these potentials have been criticized because of the charge-composition dependencies that could be 
considered as unphysical, good agreement with experiment was obtained for the structural and mechanical properties, within the domain of validity of these potentials. However, depending on the way the glass is prepared, these potentials can overestimate the density[36]. Several other potentials have been derived to simulate borosilicate glasses [37-42] but their use has been limited due to either their complexity or their failure to simulate some compositions. Three Buckingham-based potentials, proposed by Jolley et al. [43], Deng et al. [33] or Stoch et al.[44] were tested in this work. The results obtained with these different potentials have been compared to explain the potential selected for the DC simulations.

This work is organized as follows: Section 2 presents the methodology used for simulating pristine and irradiated glasses and further methods used for the analysis of results. Section 3 presents the results, first on the potential selection and then results from DC. Finally, SBN and SBNA glasses are compared and Section 4 summarizes our findings and discusses their significance.

\section{Materials and methods}

\subsection{Interatomic potentials}

The simulations presented in this study were performed using the molecular dynamics code DL_POLY [45]. The interactions between the atoms ( $\mathrm{Si}, \mathrm{B}, \mathrm{O}, \mathrm{Na}$ and $\mathrm{Al}$ ) have been calculated using potentials of the form shown below, comprising a long-range Coulomb term and a short-range Buckingham term:

$$
V_{i j}(r)=\frac{1}{4 \pi \varepsilon_{0}} \frac{q_{i} q_{j}}{r}+A_{i j} \exp \left(-\frac{r}{\rho_{i j}}\right)-\frac{C_{i j}}{r^{6}}
$$

Where $r$ is the distance between two atoms $i$ and $j, q_{i}, q_{j}$ are the effective charges of the atoms, and $A_{i j}, \rho_{i j}, C_{i j}$ are parameters describing repulsion and dispersion interactions between two atoms. Coulombic interactions were treated by the Ewald summation method[46]. Parametrizations of the Buckingham potentials proposed by Jolley et al. [43], Stoch et al.[44] and Deng et al. [33] were selected from literature for comparison (the Table enumerating the pair potential parameters can be found in supporting information). Further, depending upon the accuracy of the simulation with respect to experiment, one potential was selected for the glass preparation and the radiation effect simulations.

\subsection{Glass preparation scheme and presentation of the chemical compositions}

Pristine sodium borosilicate $(\mathrm{SBN})$ and sodium alumino-borosilicate (SBNA) glasses were simulated following the scheme shown in Fig.l. A cubic cell containing 45000 randomly placed $\mathrm{Si}, \mathrm{B}, \mathrm{O}, \mathrm{Na}$ and $\mathrm{Al}$ atoms with an initial density determined by the method detailed in Section 2.2 was first equilibrated at $4000 \mathrm{~K}$ for 100000 time steps ( 1 time step $=1 \mathrm{fs}$ ) in NVT ensemble. The structure was then quenched to room temperature $(300 \mathrm{~K})$ by decreasing the temperature $100 \mathrm{~K}$ per step in order to apply a quench rate of $5 \mathrm{~K} / \mathrm{ps}$. After quenching, the resulting glass was relaxed at room temperature and pressure in the NPT ensemble for 20000 time steps. Final relaxation of 5000 steps in NVE ensemble was applied. Periodic conditions were systematically applied throughout the simulation. 


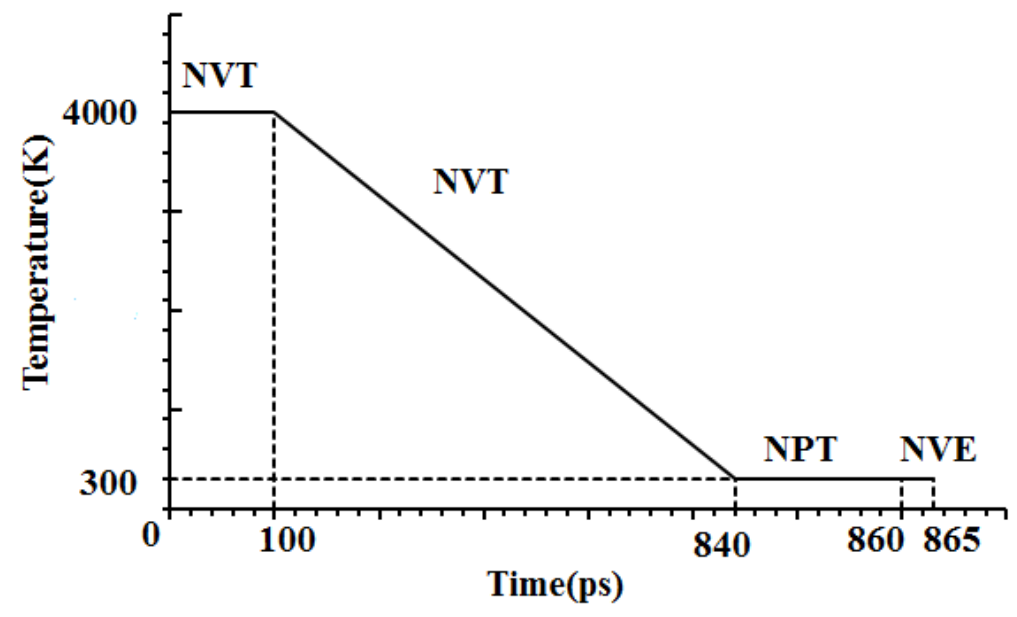

Figure 1. Glass preparation scheme by MD simulation

The following ratios are used throughout this work to define the glass compositions:

$$
\begin{gathered}
R=\frac{\mathrm{Na}_{2} \mathrm{O}}{\mathrm{B}_{2} \mathrm{O}_{3}} \\
R^{\prime}=\frac{\mathrm{Na}_{2} \mathrm{O}}{\mathrm{B}_{2} \mathrm{O}_{3}+\mathrm{Al}_{2} \mathrm{O}_{3}} \\
K=\frac{\mathrm{SiO}_{2}}{\mathrm{~B}_{2} \mathrm{O}_{3}} \\
K^{\prime}=\frac{\mathrm{SiO}_{2}}{\mathrm{~B}_{2} \mathrm{O}_{3}+\mathrm{Al}_{2} \mathrm{O}_{3}}
\end{gathered}
$$

Table 1 shows the ten glass compositions that were investigated. Four SBN compositions with $\mathrm{R}=1$ and varying $\mathrm{K}$ and four SBNA compositions with $\mathrm{R}^{\prime}=1$ and varying $\mathrm{K}^{\prime}$ were prepared. These compositions were selected specifically because aqueous alteration of such compositions has been studied by Monte Carlo simulations. Two more glasses, SBN-14 (also known as CJ1) and SBNA-CJ2 were also prepared. These glasses are closest (in terms of R and $\mathrm{R}^{\prime}$ ratios) to R7T7 glass - the French nuclear waste glass - and have been widely studied experimentally for irradiation effects and aqueous alteration.

Table 1. Glass compositions investigated here, except for $5^{\text {th }}$ and $8^{\text {th }}$ compositions, all other possess $R(S B N)=1$ and $R^{\prime}(S B N A)=1$

\begin{tabular}{|l|l|l|l|l|l|l|}
\hline S.no & Glass Name & \% $\mathbf{S i O}$ & $\mathbf{\%} \mathbf{N a}_{2} \mathbf{O}$ & $\mathbf{\% B}_{\mathbf{2}} \mathbf{O}_{\mathbf{3}}$ & $\mathbf{\%} \mathbf{A l}_{\mathbf{2}} \mathbf{O}_{\mathbf{3}}$ & $\mathbf{K}$ or $\mathbf{K}^{\prime}$ \\
\hline 1. & SBN-955 & 90 & 5 & 5 & - & 18 \\
\hline 2. & SBN-15 & 70 & 15 & 15 & - & 4.67 \\
\hline 3. & SBN-622 & 60 & 20 & 20 & - & 3 \\
\hline 4. & SBN-433 & 40 & 30 & 30 & - & 1.33 \\
\hline 5. & SBN-14/CJ1 & 67.73 & 14.23 & 18.04 & - & 3.75 \\
\hline 6. & SBNA-2 & 66 & 17 & 15 & 2 & 3.88 \\
\hline
\end{tabular}




\begin{tabular}{|l|l|l|l|l|l|l|}
\hline 7. & SBNA-5 & 60 & 20 & 15 & 5 & 3 \\
\hline 8. & SBNA-CJ2 & 61.2 & 13.3 & 18.9 & 6.6 & 2.4 \\
\hline 9. & SBNA-10 & 50 & 25 & 15 & 10 & 2 \\
\hline 10. & SBNA-12 & 46 & 27 & 15 & 12 & 1.7 \\
\hline
\end{tabular}

\subsection{Choice of the initial glass density for glass preparation}

A recent study by Kilymis et al. [10] revealed the importance of the choice of the initial density on the final glass density. Consequently, depending on the glass density, swelling or contraction can be observed after series of displacement cascades. It was observed that when the pristine glass is prepared with an initial density corresponding to the minimum of the potential energy (PE), the radiation effects are in best agreement with experimental results. A similar study by Jolley et al.[36] using current potentials, revealed that the simulated glasses with experimental density actually may not correspond to the glass with minimum PE. Hence, in order to make sure the simulated pristine glasses correspond to a minimum of the PE, a specific algorithm was applied. In this algorithm, a glass composition (4000 atoms) was prepared with different densities $(+/-15 \%$ the experimental one) using the preparation scheme shown in Fig. 1 but without the relaxation in the NPT ensemble (i.e. the volume was kept constant during the whole glass preparation). Afterwards, the potential energy and pressure of the equilibrated glass were plotted versus density and the curves were fitted to determine two equilibrium densities corresponding to the minimum PE and zero pressure, respectively (see Fig. 1). The average of the two minima, which were always very close, was taken as the effective equilibrium density. Finally, the initial density used for the pristine glass preparation (presented in Section 2.1) was taken to be 5\% larger than the effective equilibrium density to account for the slight swelling that occurs during the NPT stage at the end of the preparation.

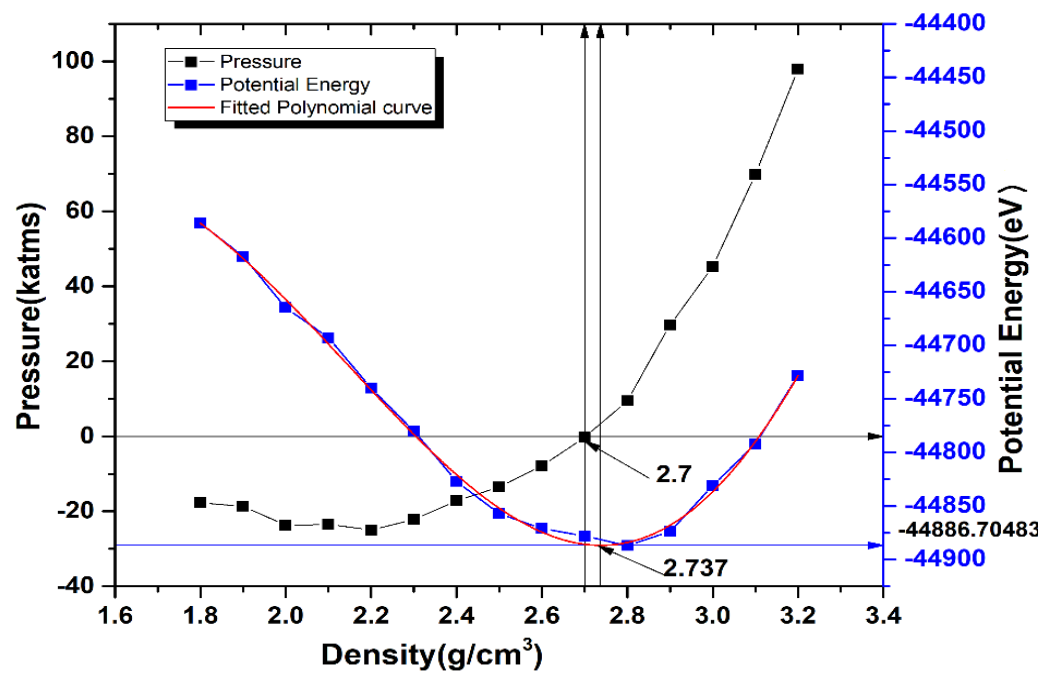

Figure 2.Pressure (black line) and total PE (blue) for SBN- when different initial densities are imposed. Arrows represent the equilibrium densities corresponding to minimum PE and zero pressure. Average of these two was taken as the effective equilibrium density 


\subsection{Simulation of series of displacement cascades}

To simulate the radiation effects, series of displacement cascades were initiated for cubic simulation cells of the SBN and SBNA glasses containing 45000 atoms and with an average edge length close to $78 \AA$. An edge length of $78 \AA$ was found to be sufficient with respect to path length of projectile (confirmed by software SRIM[47]). Before launching a series of DC in a glass, $8 \mathrm{Si}$ atoms were randomly assigned the mass of uranium (these pseudo U projectiles were otherwise treated exactly like Si atoms), and then the glass was equilibrated in NPT and NVE ensembles. The series of DC was then started by choosing U projectile and placing it at one of the corners and accordingly, the simulation cell was translated by the vector formed by the final and initial positions of the projectile. The projectile was then launched towards the center of the cell with an initial kinetic energy of $4 \mathrm{keV}$. After the first projectile was completely stopped, another projectile was selected and placed at another corner, and the procedure was repeated cycling through the 8 corners until 120 cascades are simulated. This approach ensures that the whole simulation box is progressively irradiated by the projectiles. After the last cascade, equilibrations were performed in the NPT and NVE ensembles to relieve any built-up pressure and to determine the new equilibrium volume.

To represent more precisely the atomic interactions that can occur at the short range between projectile and the glass atoms during a displacement cascade, Zeigler-Biersack-Littmark (ZBL) potentials [48] have been used. Furthermore, to ensure the continuity of energy, forces, and force derivatives between ZBL and Buckingham potentials, complementary potential with a polynomial form was introduced.

\subsection{Analysis}

\subsubsection{Non-bridging oxygens per species}

To study the change in the polymerization level, the numbers of non-bridging oxygens (NBO) per species before and after DC were compared. The number of NBO per species was calculated using the formula given below:

$$
N B O / \text { Species }=\frac{\sum_{n=0}^{4} Q_{n} *(4-n)}{\sum_{n=0}^{4} Q_{n}}
$$

Where $\mathrm{Q}_{\mathrm{n}}$ represents fourfold-coordinated $\mathrm{Si} / \mathrm{B} / \mathrm{Al}$ atoms with $n$ bridging oxygens $(\mathrm{BO})$ and 4 $-n$ NBOs. Similarly for the case of trigonal boron,

$$
N B O / \text { Species }=\frac{\sum_{n=0}^{3} T_{n} *(3-n)}{\sum_{n=0}^{3} T_{n}}
$$

Where $\mathrm{T}_{\mathrm{n}}$ represents threefold-coordinated $\mathrm{B}$ atoms with $n$ BOs and $3-n \mathrm{NBO}$.

\subsubsection{Number of triplets and comparison to chemical random mixing}

To quantify the degree of chemical ordering in each glass, the number of triplets obtained assuming random mixing were compared to the number of triplets in the simulated glass.

Number of triplets on random mixing are calculated as follows [49]. If $\mathrm{N}_{\mathrm{O}_{2}}$ corresponds to the number of two coordinated $\mathrm{O}$, the number of $\mathrm{F} 1-{ }^{2} \mathrm{O}-\mathrm{F} 2$ triplets $\left(\mathrm{F}_{1}\right.$ and $\mathrm{F}_{2}$ are two network former atoms) that would be obtained in the case of a chemical random mixing is given by:

$$
\mathrm{F}_{1}{ }^{2} \mathrm{O}-\mathrm{F}_{2}=N_{O_{2}} * P_{F 1 F 2}
$$


$P_{F 1 F 2}$ is the probability of forming one $\mathrm{F}_{1}-{ }^{2} \mathrm{O}-\mathrm{F}_{2}$ triplet in a structure containing $N_{F_{1}}$ bonds of type $\mathrm{F}_{1}-{ }^{2} \mathrm{O}$ and $N_{F_{2}}$ bonds of type $\mathrm{F}_{2}{ }^{2} \mathrm{O}$. Two cases must be distinguished.

Case 1: $F_{1}$ and $F_{2}$ are different former types

$$
\mathrm{P}_{\mathrm{F} 1 \mathrm{~F} 2}=2 * \frac{\mathrm{N}_{\mathrm{F}_{1}} * \mathrm{~N}_{\mathrm{F} 2}}{\mathrm{~N}_{\mathrm{F}}\left(\mathrm{N}_{\mathrm{F}}-1\right)}
$$

Where, $N_{F}=N_{F_{1}}+N_{F_{2}}$

Case 2: $F_{1}$ and $F_{2}$ are the same former type

$$
P_{F 1 F 1}=\frac{N_{F_{1}} *\left(N_{F_{1}}-1\right)}{N_{F}\left(N_{F}-1\right)}
$$

\section{Results}

\subsection{Force field selection}

Structural properties of the SBN-14 glass prepared with each potential were compared with experimental results (Table 2). The Jolley and Stoch potentials underestimated the glass density by $8 \%$ and $2 \%$, respectively, whereas the Kieu potential overestimated the density by $11 \%$. The average boron coordination was poorly estimated by the Jolley and Stoch potential, the Kieu potential gave an estimate within $1.5 \%$ of the experimental value. Other structural properties such as the average bond angle and bond length were also best estimated by the Kieu potential.

Hence, all the glasses in Table 1 were prepared with the Kieu potential for the ternary glasses and the Deng potential for the quaternary glasses (the Deng and Kieu potentials are strictly identical for the ternary glasses and the Deng potential allows for $\mathrm{Al}_{2} \mathrm{O}_{3}$ in the composition to be simulated). SBN-14, in particular, was prepared with both the Kieu and Jolley potentials to study how radiation effects may be impacted by the nature of the potential.

Table 2. $\mathrm{SBN}-14\left(67.73 \% \mathrm{SiO}_{2} .14 .23 \% \mathrm{Na}_{2} \mathrm{O} .18 .04 \% \mathrm{~B}_{2} \mathrm{O}_{3}\right)$ prepared with three different potentials. This table compares results from three potentials with experimental results. $\left({ }^{\#} C_{B}\right.$

\begin{tabular}{|c|c|c|c|c|}
\hline \multirow[t]{2}{*}{ Parameter } & \multicolumn{3}{|c|}{ Simulation Results } & \multirow{2}{*}{$\begin{array}{l}\text { Experimental } \\
\text { Results[35] }\end{array}$} \\
\hline & $\begin{array}{l}\text { Jolley } \\
\text { Potential }\end{array}$ & $\begin{array}{l}\text { Stoch } \\
\text { Potential }\end{array}$ & $\begin{array}{l}\text { Kieu } \\
\text { Potential }\end{array}$ & \\
\hline $\begin{array}{l}\text { Equilibrium } \\
\text { Density }\left(\mathrm{g} / \mathrm{cm}^{3}\right)\end{array}$ & 2.25 & 2.50 & 2.73 & 2.45 \\
\hline${ }^{\#} \mathbf{C}_{\mathrm{B}}$ & 3.48 & 3.17 & 3.78 & 3.73 \\
\hline $\mathbf{S i - O}(\AA)$ & 1.62 & 1.63 & 1.60 & $1.60-1.62$ \\
\hline B-O(A) & 1.49 & 1.46 & 1.47 & $1.37-1.47$ \\
\hline $\mathbf{N a - O ( \AA )}$ & 2.55 & 2.44 & 2.52 & $2.29-2.62$ \\
\hline Si-Si(A) & 3.18 & 3.15 & 3.06 & 3.08 \\
\hline Si-O-Si & 157.0 & 147.2 & 145.2 & 144-147 \\
\hline
\end{tabular}
represents mean boron coordination) 


\begin{tabular}{|l|l|l|l|l|}
\hline O-B-O & 113.0 & 116.8 & 110.7 & $\mathbf{1 1 1 . 6 - 1 1 8 . 6}$ \\
\hline B-O-B & 152.1 & 148.0 & 136.4 & $\mathbf{1 2 9 . 4 - 1 4 3}$ \\
\hline
\end{tabular}

The pressure change with deposited energy is first presented, followed by results for all the glasses before (BDC) and after (ADC) the DC series. This section is divided into subsections dedicated to density, short-range order, intermediate-range order, network connectivity, randomness and chemical mixing.

\subsubsection{Evolution of pressure with deposited energy}

Pressure change inside the glass with deposited energy (i.e. the energy deposited by the cascade projectiles) was followed, see Figure 3. Evolution of pressure inside different SBN (left) and SBNA (right) glass compositions with accumulation of cascades

. This shape of the curve - an initial rapid rise, followed by an increasingly gentler slope until saturation is reached, for a deposited energy in the range 4-6 eV/atom - is qualitatively consistent with experimental results [2] and with simulations performed by Kilymis et al. [30,50,51]. For SBN-14 subjected to series of 120 (4 keV each) and 190 (0.8 keV each) displacement cascades, saturation was attained at $6 \mathrm{eV} /$ atom[50] and $8 \mathrm{eV} /$ atom [10] respectively, which corresponds to an equivalent dose of $4.3 \times 10^{18} \alpha / \mathrm{g}\left(\right.$ or $9.8 \times 10^{21} \mathrm{keV} / \mathrm{cm}^{3}$ ). Even though the total pressure accumulated at the end of the DC is different for different compositions, the saturation threshold has been reached in all cases. In several studies on doped, externally irradiated or simulated glasses $[11,18,29]$, saturation in density, hardness and other structural properties were observed around $2 \times 10^{18} \alpha / \mathrm{g}$ or a nuclear dose of $10^{21}$ $\mathrm{keV} / \mathrm{cm}^{3}$. This also implies that irrespective of the composition, system size and projectile energy, the internal pressure threshold is reached in all cases around the similar accumulated dose.
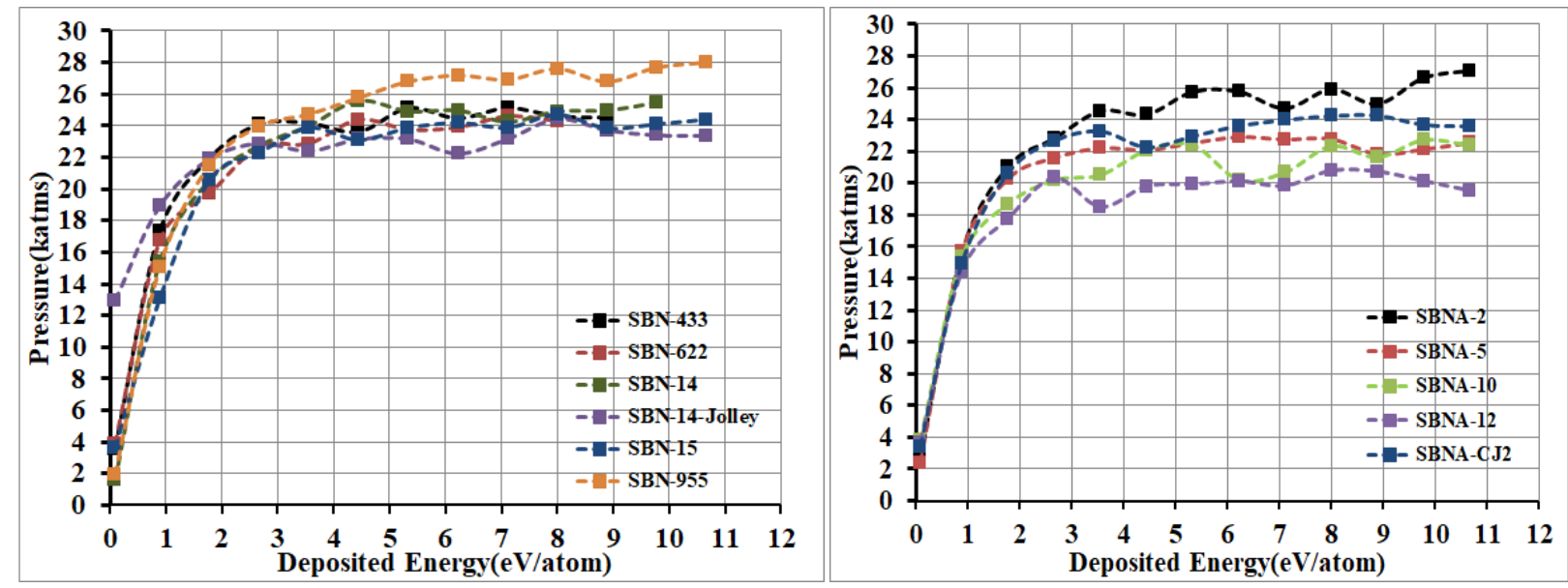

Figure 3. Evolution of pressure inside different SBN (left) and SBNA (right) glass compositions with accumulation of cascades

\subsubsection{Density}

Densities before and after DC are plotted for SBN and SBNA glasses in Fig. 4 against $K$ and $K^{\prime}$ ratio, respectively. In general, glass density increased with an increasing $K$ or $K^{\prime}$ up to a value of approximately 3 and then decreased. SBN-955 ( $K=18$ not shown in Fig. 4) had a higher final density $\left(2.77 \mathrm{~g} / \mathrm{cm}^{3}\right)$ than expected and there could be two possible explanations for this: (a) the dependence of density on the quenching temperature, in particular some fivefold-coordinated Si species were found, which might contribute to the high density (b) the 
low number of $\mathrm{Na}$ and $\mathrm{B}$ atoms, which reduces the chances for $\left[\mathrm{BO}_{4}\right]^{-}+\mathrm{Na}$ entities to form and favoring $\mathrm{BO}_{3}$, in fact almost half of $\mathrm{Na}$ was used up in placing NBOs' on $\mathrm{Si}$ and ${ }^{[3]} \mathrm{B}$.

Fig. 4 shows that density of each glass decreased after DC. Swelling of approximately 4-9\% was observed in SBN glasses and 4-5\% in SBNA glasses. Similar swelling in borosilicate glasses with the amplitude depending upon composition and irradiation conditions, has been observed in studies with doped glasses $(0.5-0.6 \%$ [11,13]), external irradiation $(1.3-2.4 \%$ $[52,53])$, and simulations $(3-7 \%[28,30,54])$.

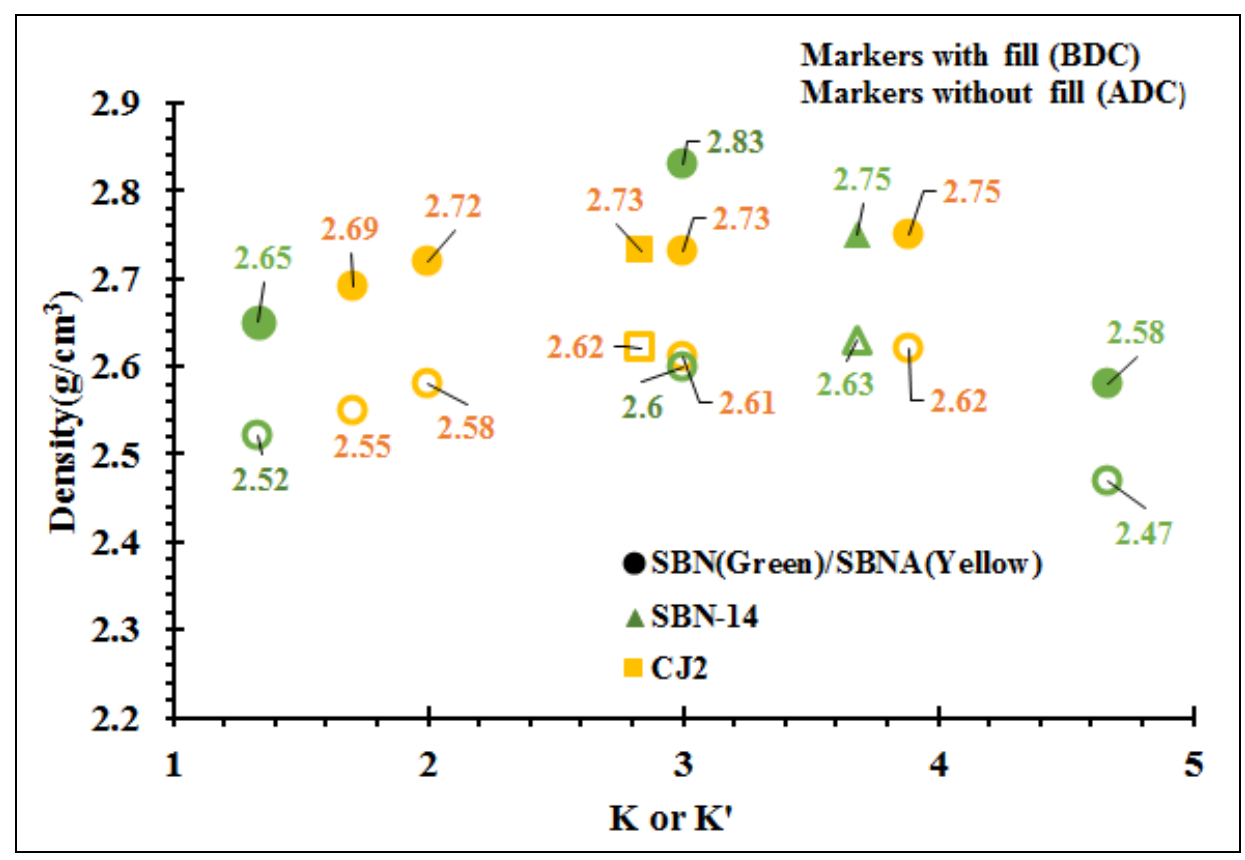

Figure 4. Variation of density with $K$ and $K$ ' ratios for SBN (Green marker) and SBNA (Blue marker), before (filled circles) and after (empty circles) series of 120 DC

\subsubsection{Short and medium range orders}

The effect of irradiation on short-range order can be evaluated by following the change in coordination of glass formers. Each cation has a well-defined coordination state corresponding to a tetrahedral or triangular local environment. These local entities act as building blocks and exhibit order at the level of several associated ions, and this order extends over around $1 \mathrm{~nm}$ defining the medium-range order. Any change in short- and medium-range orders will also lead to change in radial distribution functions.

\subsubsection{Coordination of glass formers}

$\mathrm{Si}$ and $\mathrm{Al}$ essentially remained in tetrahedral coordination after DC (data not shown) as evidenced by a change of less than $0.1 \%$ in the average $\mathrm{Si}$ and $\mathrm{Al}$ coordination. This result is consistent with their high field strengths.

The non-linear trend observed in Fig. 5, for mean boron coordination $\left(\mathrm{C}_{\mathrm{B}}\right)$ with composition, is in agreement with the Dell and Bray model and experimental results [55,56] . At high $K$ $\left(K^{\prime}\right)$ (low alkali concentration), Na primarily acts as charge compensator converting ${ }^{[3]} \mathrm{B}$ to ${ }^{[4]} \mathrm{B}$, resulting in a gradual increase of $\mathrm{C}_{\mathrm{B}}$. As $K\left(K^{\prime}\right)$ starts to decrease (increasing alkali concentration), $\mathrm{Na}$ changes its role to a network modifier leading to low $\mathrm{C}_{\mathrm{B}}$ values.

After DC, $\mathrm{C}_{\mathrm{B}}$ decreased on an average by $2-4 \%$ for SBN and $3-4 \%$ for SBNA (Figure ). In other words, a decrease in ${ }^{[4]} \mathrm{B}$ of the order $12-22 \%$ and $14-30 \%$ for SBN and SBNA, respectively, was estimated. Studies conducted with external irradiation have shown a similar decrease, 13-30\%[52,53] in ${ }^{[4]} \mathrm{B}$, whereas, doped glasses [53] and glasses prepared with high quenching rate $[57,58]$ showed lesser decrease about $7 \%$ in ${ }^{[4]} \mathrm{B}$. 
The decrease in $\mathrm{C}_{\mathrm{B}}$ has often been associated with the thermal history of glass preparation $[2,28,57]$. In terms of ballistic effects, it can be understood as when the heavy projectile traverses through the glass, it losses its energy by elastic collisions, which leads to a sharp rise in temperature for a short time at the center of the cascade and eventually, the glass is rapidly quenched under the influence of the surrounding material still at room temperature. It has been observed that the chemical equilibrium described by Equation (7) is shifted towards the right when temperature increases $[58,59]$. So ${ }^{[3]} \mathrm{B}$ formation is favored in cascade core, and a part of it, is retained due to the very high quench rate following the displacement cascade explaining the ${ }^{[3]} \mathrm{B}$ concentration increase under irradiation.

$$
\mathrm{BO}_{4}^{-}+\mathrm{Na}_{\text {charge compensator }}^{+} \leftrightarrow \mathrm{BO}_{3}+\mathrm{O}_{n b}^{-}+\mathrm{Na}_{\text {Modifier }}^{+}
$$

The decrease in $\mathrm{C}_{\mathrm{B}}$ also implies change in $\mathrm{Na}$ role from charge compensator to network modifier. This might have an effect on chemical durability.
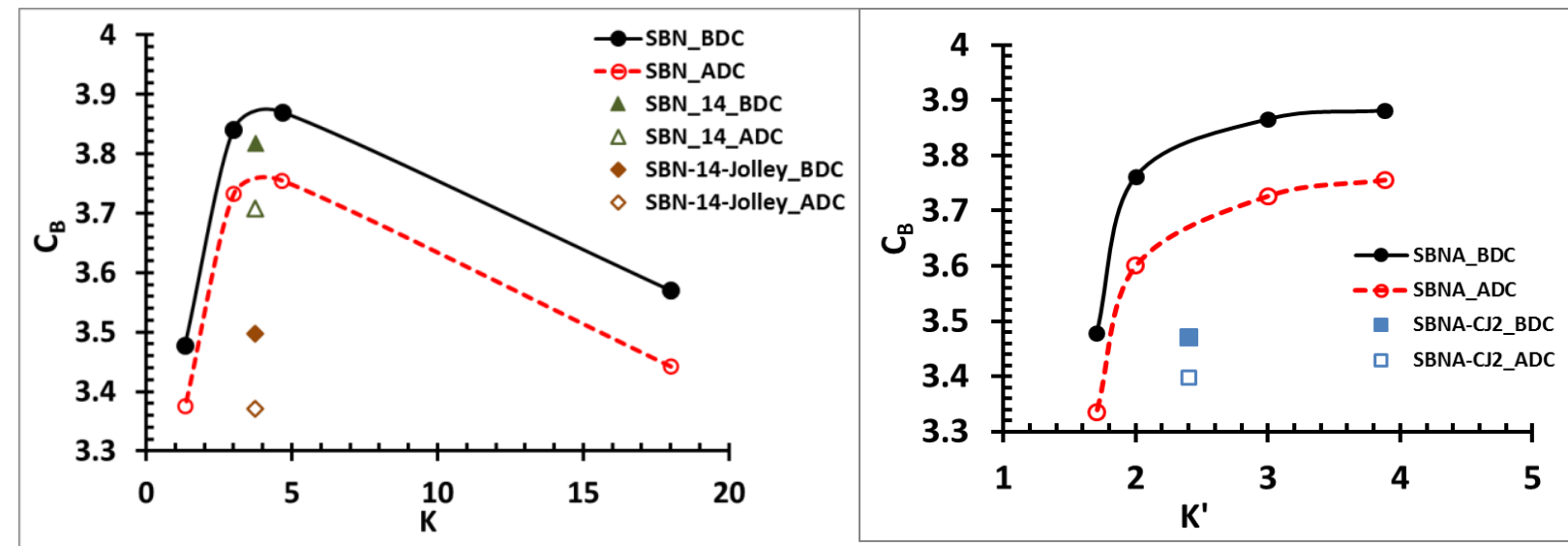

Figure 5. Variation of average $B$ coordination with $K$ and $K^{\prime}$ ratio, for $S B N$ (left) and $S B N A$ (right) respectively, before (solid line) and after (dotted line) series of DC.

\subsubsection{Radial distribution functions ( $R D F)$}

$\mathrm{RDF}$ of Si-O and Al-O have single peaks with no significant change in their position but slight broadening after series of DC, see Figs. 6 and 7, which is in agreement with no significant coordination change observed for $\mathrm{Si}$ and $\mathrm{Al}$ and increase in disorder.

For the B-O RDF, the curve has two peaks depending on boron coordination, peak on left side depicts ${ }^{[3]} \mathrm{B}$ and other peak after that depicts ${ }^{[4]} \mathrm{B}$. Comparing SBN glasses in Fig. 6, top 2 plots, it can be seen for SBN-14 with Jolley's potential, even before DC, majority of B are in ${ }^{[3]} \mathrm{B}$ as compared to Kieu's potential and the Si-O RDF has shifted slightly to the right. Other four figures compare glasses with decreasing $\mathrm{B}_{2} \mathrm{O}_{3}$ or increasing $\mathrm{SiO}_{2}$ content (From SBN-433 to SBN-955).

After irradiation, in general, RDF for B-O can be seen shifting towards left. Decrease in population of ${ }^{[4]} \mathrm{B}$ and corresponding increase in ${ }^{[3]} \mathrm{B}$, leading into decrease in average bond length, $r_{B-O}$, since

$$
r_{B-O\left(3_{B}\right)}(1.37 \AA)<r_{B-O\left(4_{B}\right)}(1.47 \AA) .[34]
$$




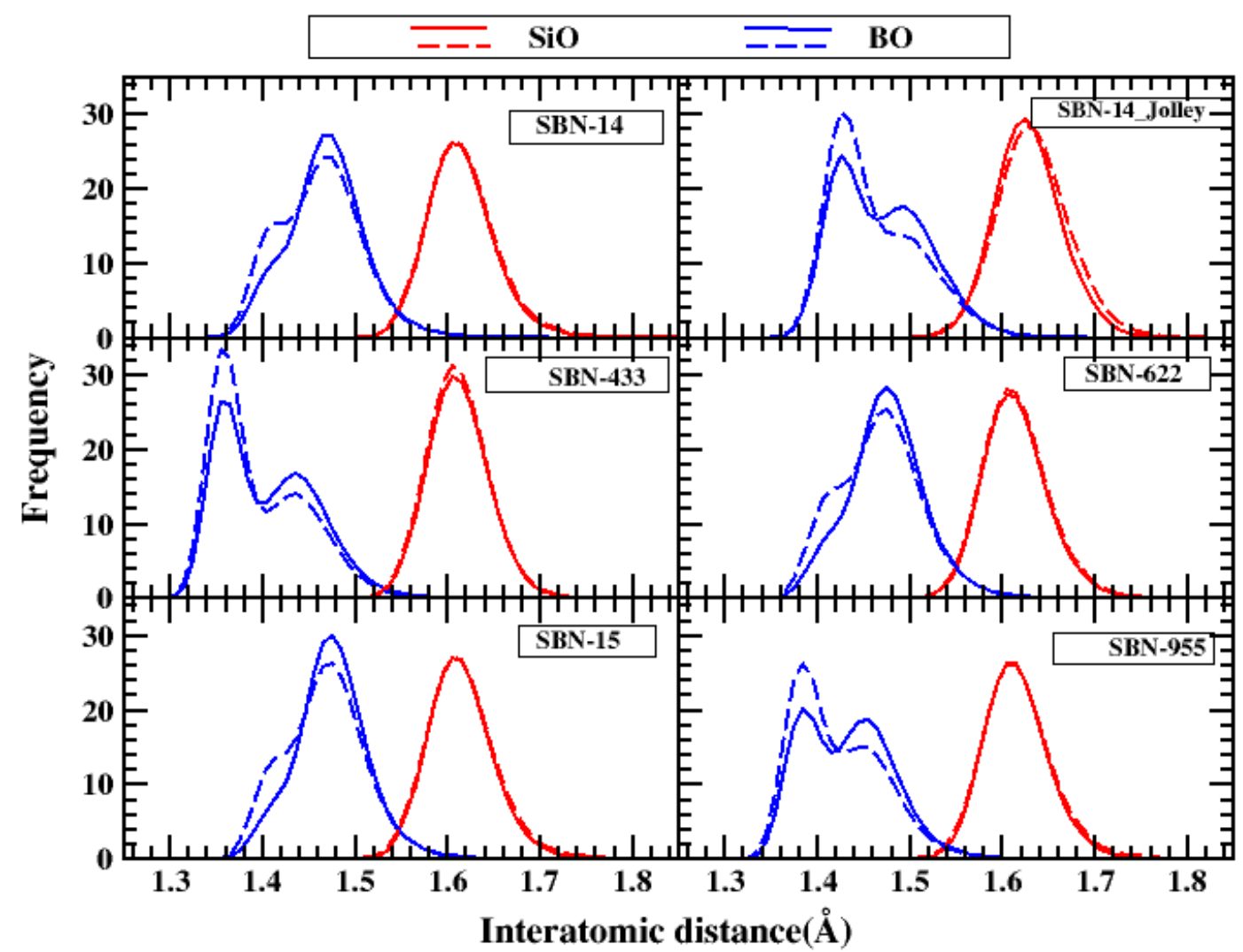

Figure 6. Radial distribution functions for SBN glasses before (solid line) and after (dotted line) series of DC. Top two are SBN-14 glass prepared with different potentials and then glasses have been put in order of increasing silica content

All SBNA compositions possess $15 \%, \mathrm{~B}_{2} \mathrm{O}_{3}$ and although concentration of $\mathrm{Na}_{2} \mathrm{O}$ is increased with increasing $\mathrm{Al}_{2} \mathrm{O}_{3}$ concentration such that all of $\mathrm{Al}$ is compensated first. Still, with increasing $\mathrm{Al}_{2} \mathrm{O}_{3}$ or decreasing $\mathrm{SiO}_{2},{ }^{[4]} \mathrm{B}$ is seen decreasing ( see Fig.7). It is interesting to note that ${ }^{[3]} \mathrm{B}$ peak is prominent for SBNA-12, although, there is not much difference between SBNA-12 and SBNA-10 composition. This may imply boron anomaly threshold for these SBNA glasses and it will be seen in next section that there is indeed higher fraction of NBOs' in this composition. 


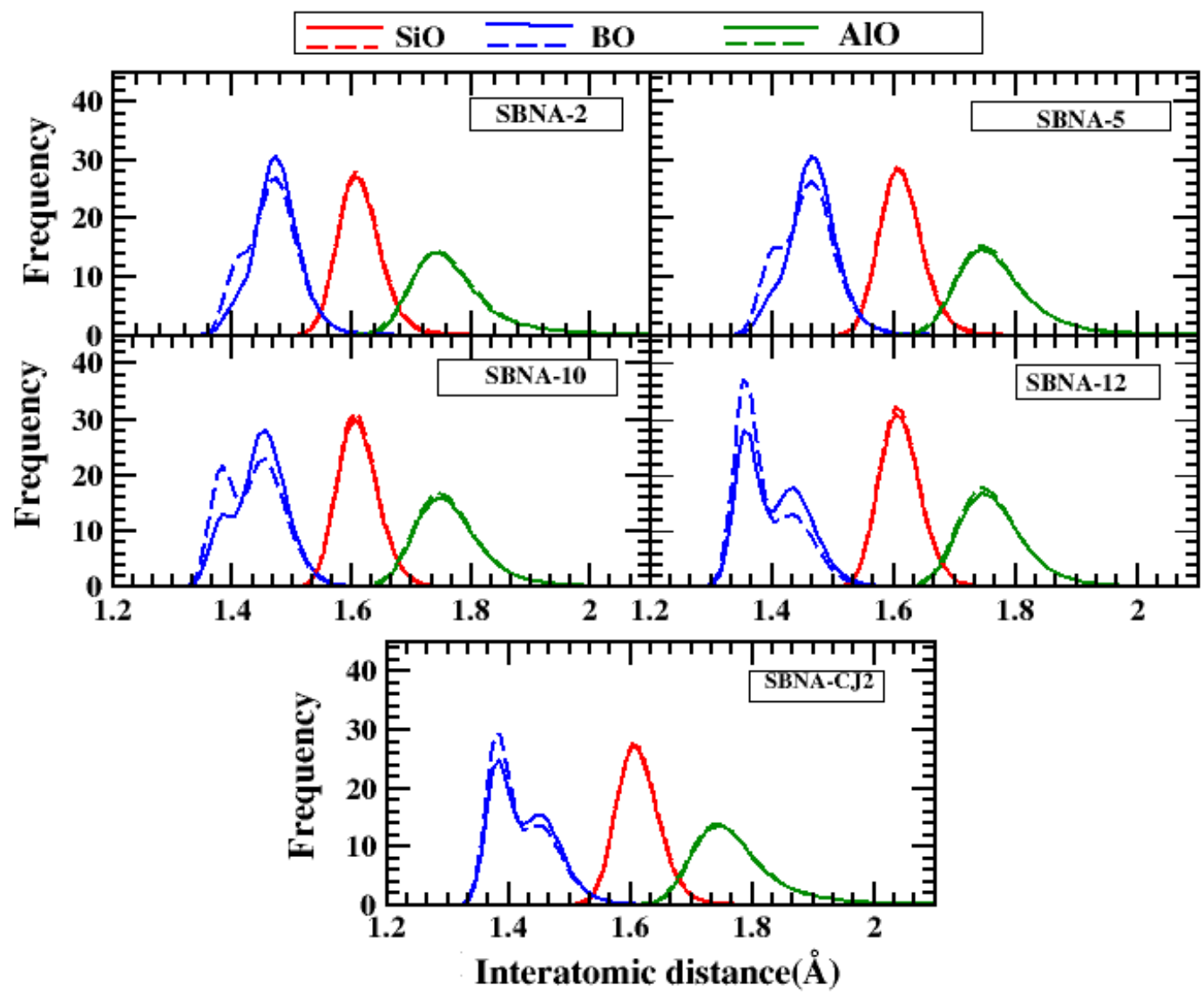

Figure 7. Radial distribution functions for SBNA glasses before (solid line) and after (dotted line) series of DC. Except for SBNA-CJ2 (bottom) all other compositions contain $15 \% \mathrm{~B}_{2} \mathrm{O}_{3}$ and have been put in order of increasing alumina content

3.1.4. Network connectivity

Connectivity of a glassy network can be determined by the number and arrangement of bridging and non-bridging bonds which link each of the building blocks to their neighbors. Thus, entities $\mathrm{Q}_{\mathrm{n}}$ and $\mathrm{T}_{\mathrm{n}}$ are analyzed to determine the connectivity of the network.

\subsubsection{1. $Q_{n}$ and $T_{n}$ Distribution}

Figs. 8-11 can be correlated with section 3.2.3.1, wherein $\mathrm{C}_{\mathrm{B}}$ was seen to increase with $K$ and at low $K$ ratio, $\mathrm{Na}$ was referred to as network modifier. Indeed at low $K$ (or high alkali concentration), there is higher fraction of low order $\mathrm{Q}_{\mathrm{n}}$ and $\mathrm{T}_{\mathrm{n}}$ for both the type of glasses.

Comparing evolution after series of DC for each former. For Si (see Figs. 8 and 9), a decrease in the range 3-7\% (for SBN) and 1-4\% (for SBNA) in $\mathrm{Q}_{4}$ and corresponding increase in $\mathrm{Q}_{3}$, $\mathrm{Q}_{2}$ and $\mathrm{Q}_{1}$, indicating decrease in Si connectivity after series of DC. In a study by Peuget et. al., NMR characterization of borosilicate glass irradiated by gold ions revealed slightly higher proportion of $\mathrm{Q}_{3}$ after irradiation[52]. 

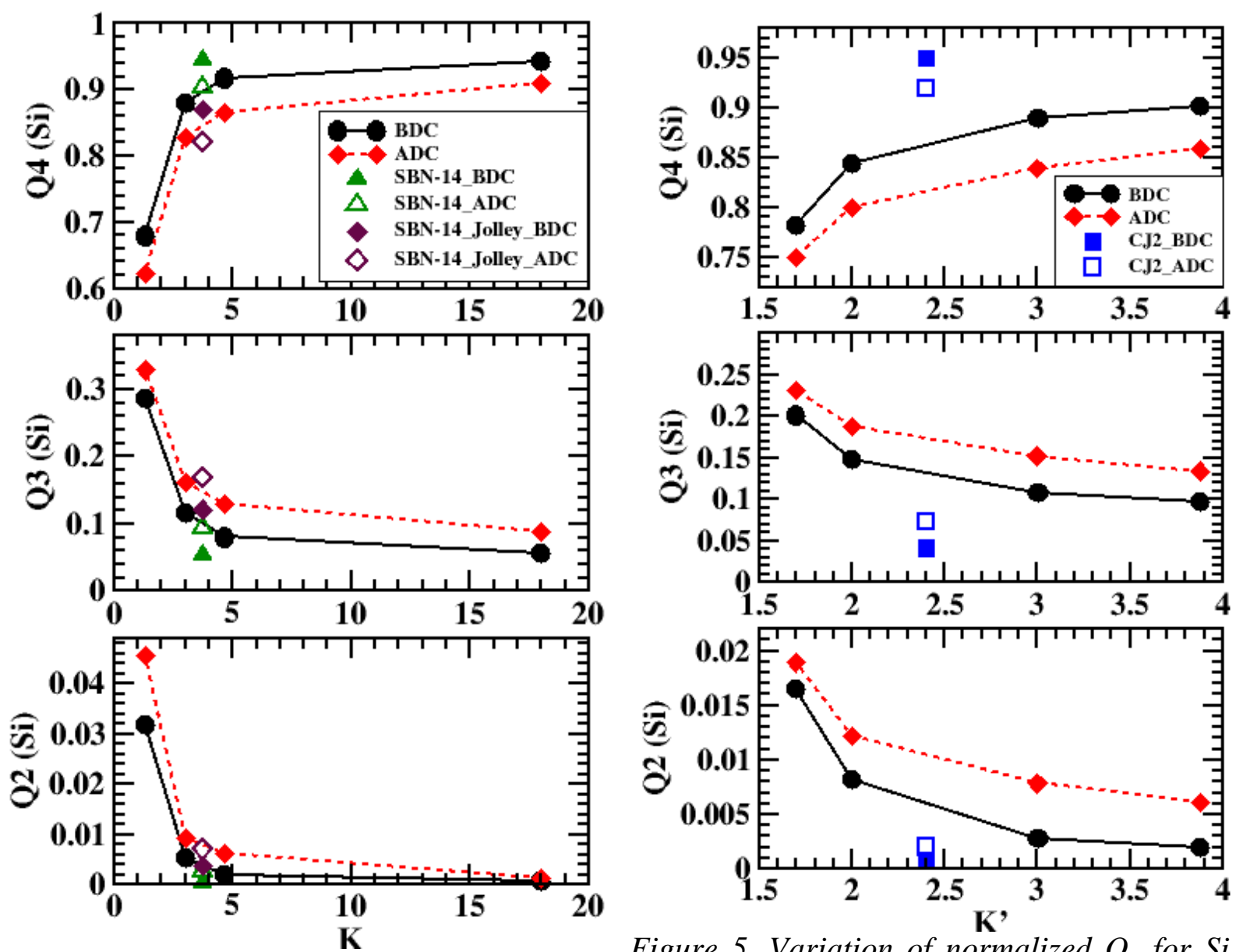

Figure 8. Variation of normalized $Q_{n}$ for $S i$ with $K$ ratio for different $S B N$ glasses, before (solid line) and after (dotted line) series of $D C$

Figure 5. Variation of normalized $Q_{n}$ for $S i$ with $K$ ' ratio for different $S B N A$ glasses, before (solid line) and after (dotted line) series of $D C$

For B (see Figs. 10 and 11), decrease in $\mathrm{T}_{3}$ was estimated, almost 2-6\% of $\mathrm{T}_{3}$ transforms to $\mathrm{T}_{2}$ and $\mathrm{T}_{1}$, which means, a fraction of NBO is also placed on ${ }^{3} \mathrm{~B}$ entities. Looking at the $\mathrm{Q}_{\mathrm{n}}$ for $\mathrm{B}$, a decrease in $\mathrm{Q}_{4}$ by 1-4\% and corresponding increase in $\mathrm{Q}_{3}$ is seen. 

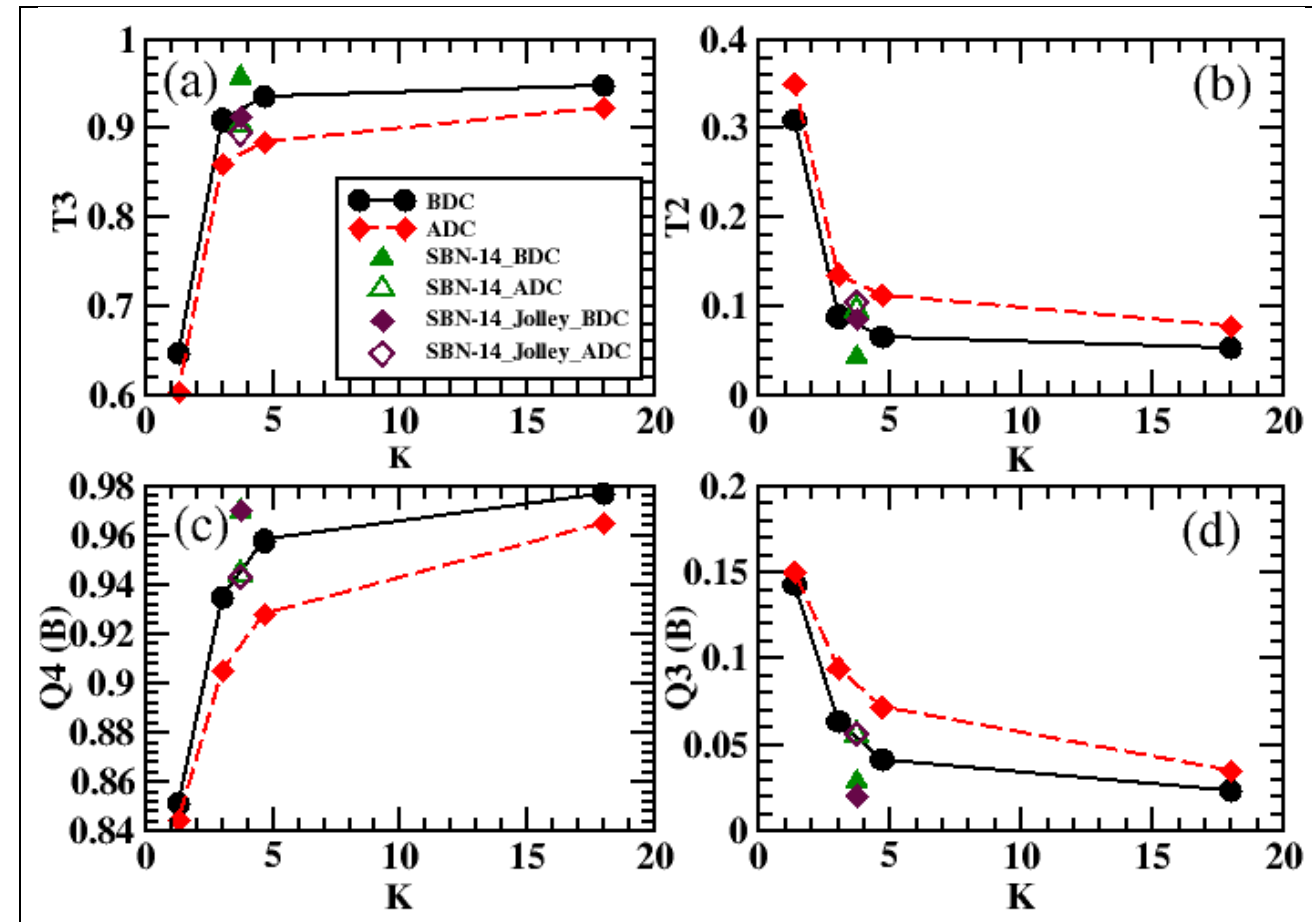

Figure 60.Variation of $Q_{n}$ and $T_{n}$ for $B$ with $K$ ratio for different $S B N$ glasses, before (solid line) and after (dotted line) series of $D C$

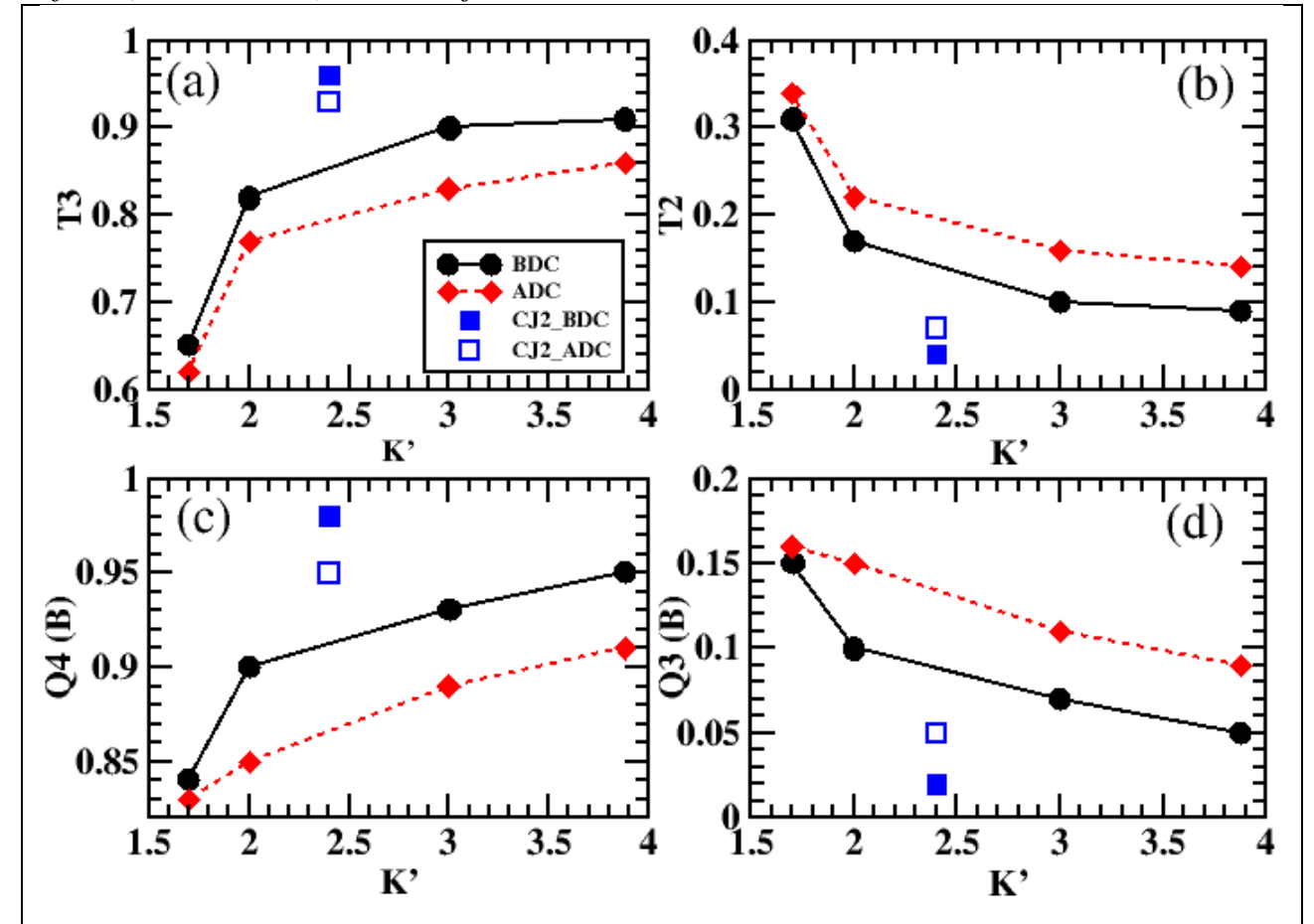

Figure 71.Variation of $T_{n}$ and $Q_{n}$ for $B$ with $K$ ' ratio for different $S B N A$ glasses, before (solid line) and after (dotted line) series of $D C$

Majority of $\mathrm{Al}$ were present as $\mathrm{Q}_{4}$ (not shown here), however there was a decrease in the range 1.6-4.6\% (depending upon composition) in $\mathrm{Q}_{4}$ and corresponding increase in $\mathrm{Q}_{3}$ and $\mathrm{Q}_{2}$ species after DC.

This increase in fraction of low order $Q_{n}$ and $T_{n}$ entities can be correlated with the creation of $\mathrm{NBO}$, when $\mathrm{BO}_{4}$ transforms to $\mathrm{BO}_{3}$ under irradiation, see Equation 5. Available sodium, which was earlier acting as a charge compensator near a $\left[\mathrm{BO}_{4}\right]^{-}$unit, now changes its role and 
acts as network modifier around the $\mathrm{Si}, \mathrm{B}$ and $\mathrm{Al}$ formers. NBO distribution will be discussed in next section.

\subsubsection{NBO distribution}

Before DC maximum number of NBOs' on Si species (except for SBNA-12) followed by B and then Al, see Figs. 12 and 13, and further after DC, there is an increase in NBOs' on each species (dashed lines). For $\mathrm{Si}, \mathrm{B}$ and $\mathrm{Al}$ the percentage increase was in the range 13-40\%, 17 $50 \%$ and $39-42 \%$, respectively. A closer look at NBOs' placed on ${ }^{[3]} \mathrm{B}$ and ${ }^{[4]} \mathrm{B}$, Figs. $13(b)$ and $14(b)$, show higher proportion of NBOs' on ${ }^{[3]} \mathrm{B}$, especially at low $\mathrm{K}$. This is in agreement with Dell and Bray model for borosilicate glasses, as well as with other experimental studies on borosilicate glasses [56]. Further, after series of DC slightly higher fraction of NBOs' was estimated on ${ }^{[3]} \mathrm{B}$ entities.
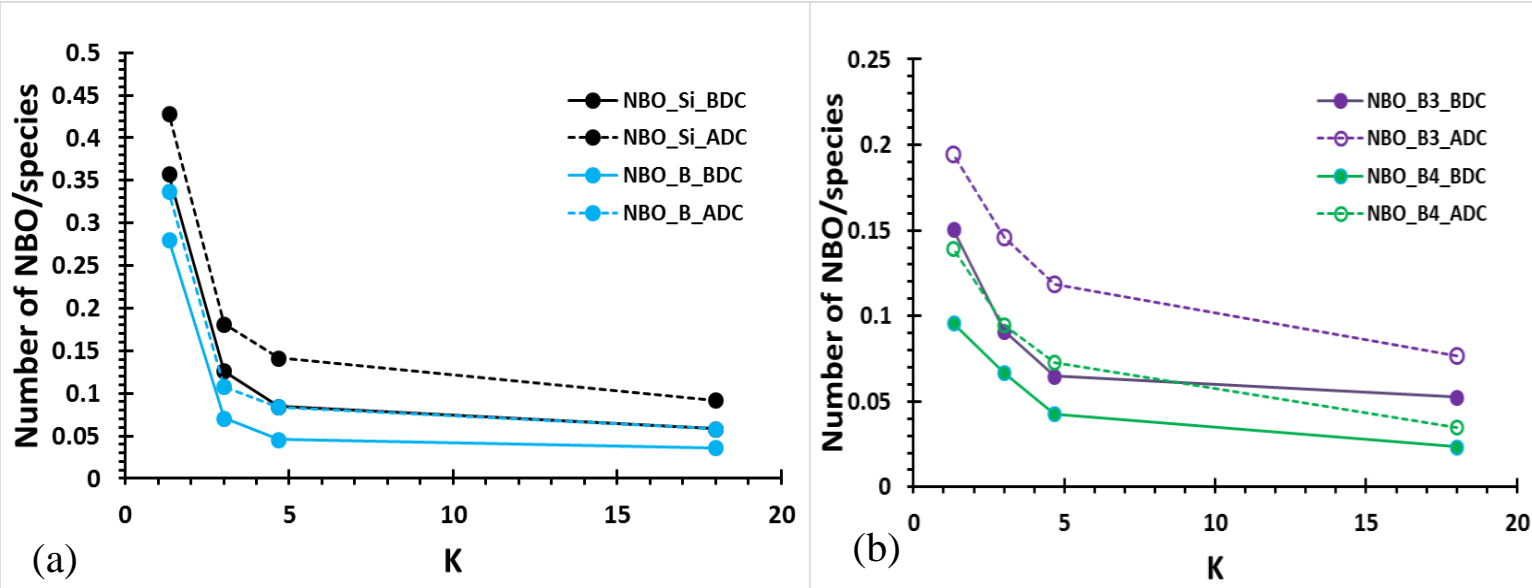

Figure 8. Variation in number of, (a). NBO per Si or B species (b). NBO per trigonal $(3 B)$ and tetrahedral (4B) species, with $K$ ratio for $S B N$ glasses, before (solid line) and after (dotted line) series of $D C$

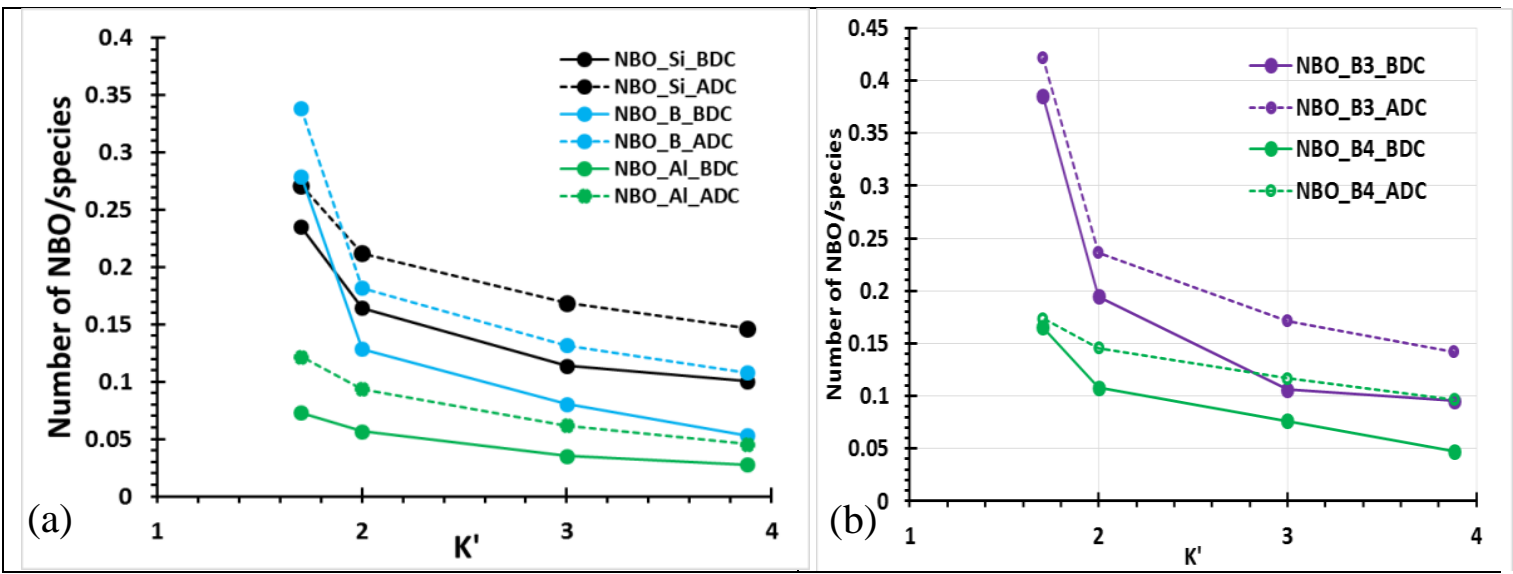

Figure 9. Variation in number of, (a). NBO per Si, B or Al species (b). NBO per trigonal $(3 B)$ and tetrahedral $(4 B)$ species, with $K$ ' ratio for $S B N A$ glasses, before (solid line) and after (dotted line) series of $D C$

\subsubsection{Ring distribution}

Though glasses are amorphous and expected to exhibit a high degree of disorder, within themselves, it has been observed that there exist rings and chains of building blocks connected in a manner closely found in crystals, but yet not extending over long range distances. Distribution of such entities is said to provide a degree of intermediate range order to the structure[2,60]. 
The glass topologies have been studied by analyzing rings statistics using software R.I.N.G.S [61]. The rings are composed of $\mathrm{Si}, \mathrm{Al}$ and $\mathrm{B}$ connected by $\mathrm{O}$ atoms. For SBN glasses (Fig.14), pristine or irradiated, it can be seen with increasing silica content there is narrowing of distribution around 6,7,8,9 membered rings. Similarly for SBNA glasses (Fig.15), with increasing alumina and decreasing silica, the distribution can be seen widening. This underlines the strong order imposed by the silica in the glass network because of the very rigid $\mathrm{SiO}_{4}$ entities.

The ring distributions for all the glasses broaden after DC (Figs.14 and 15). In general there is an increase in number of small and large rings and decrease in number of intermediate rings. Further, there is also decrease in total number of ring entities (by 4-6\%), which is in agreement with the depolymerisation induced by the NBO formation. It has been observed in that after irradiation, there is broadening of ring distribution and an increase in population of 3 members' ring [2,27,62]. In fact, this increase of structural disorder in the glass topologies can be explained by the increase in fictive temperature induced by ballistic effects. This higher entropy is again associated to the increase of the quench rate inside the cascade cores leading to a less stable (i.e. characterized by a higher internal energy) final structure.
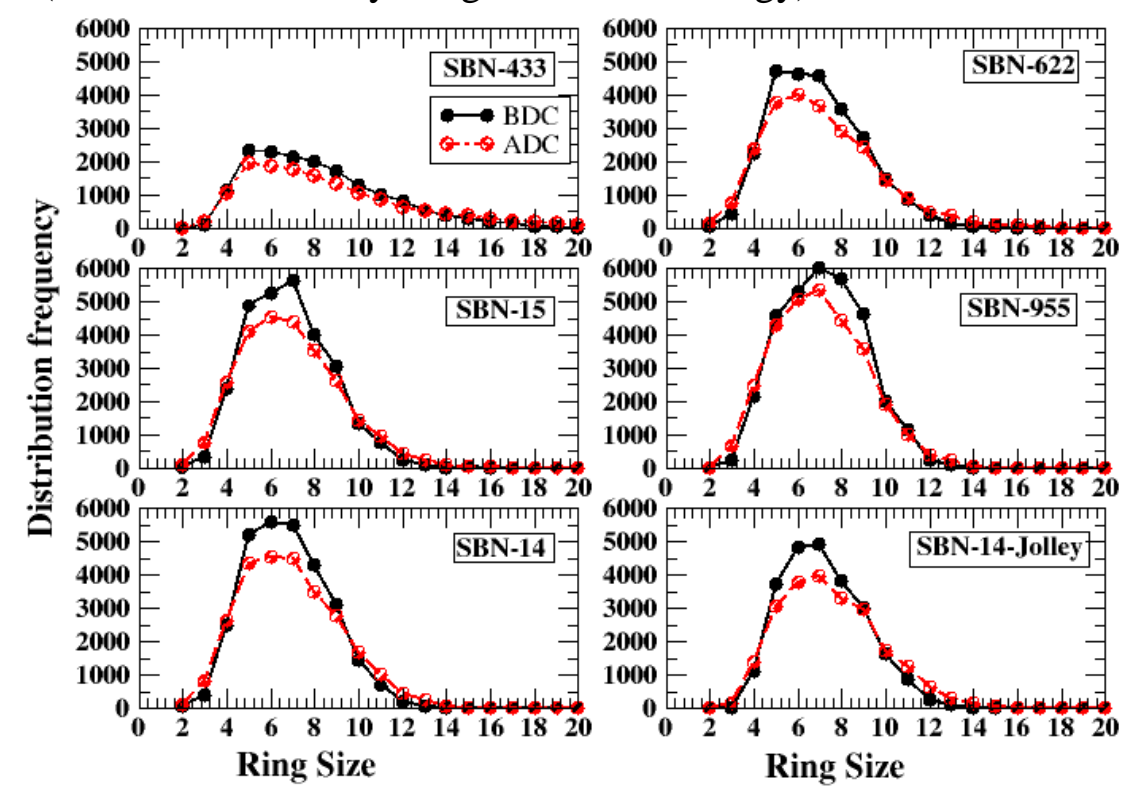

Figure 10. Ring size distribution for different SBN glasses before (solid line) and after (dotted line) series of DC. From top, glasses have been arranged in order of increasing silica content until SBN-955, after that SBN-14 prepared with two different potentials. 

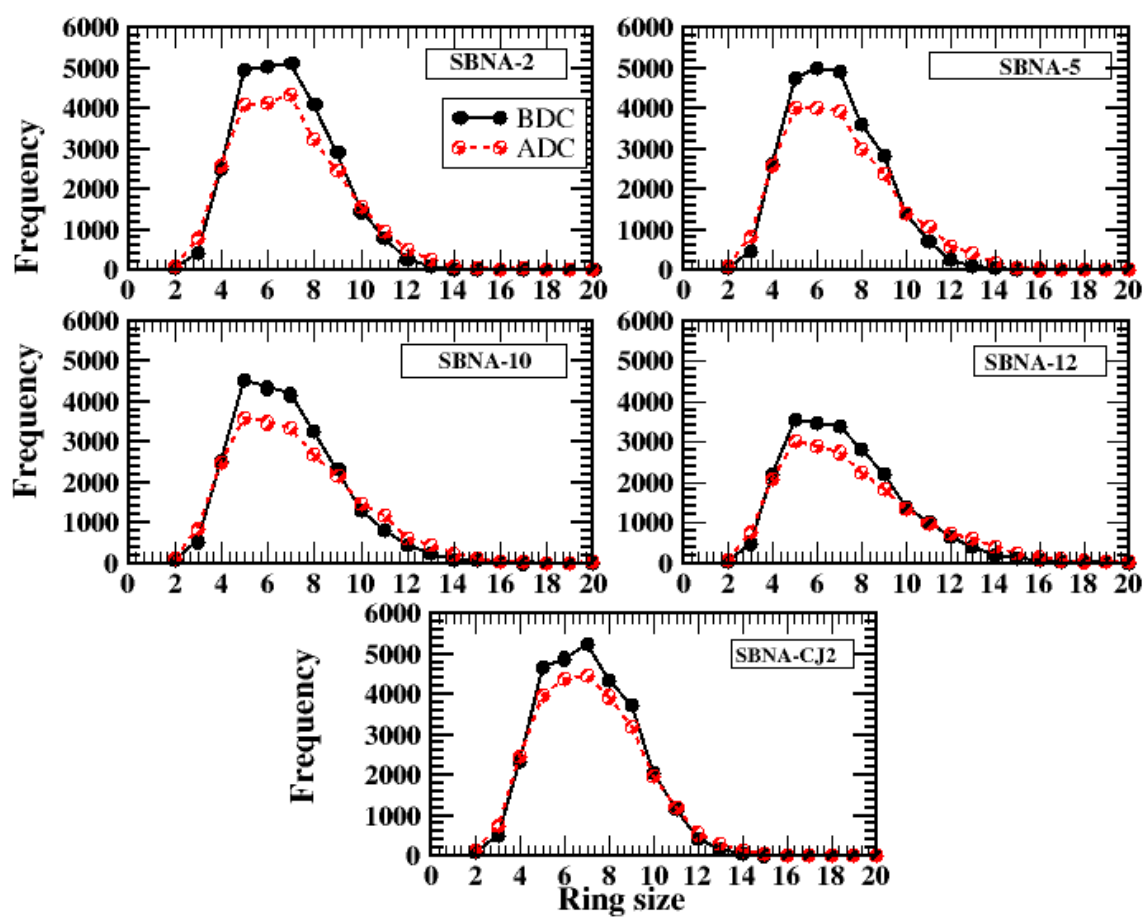

Figure 11. Ring size distribution for different SBNA glasses before (solid line) and after (dotted line) series of DC. From top, glasses have been arranged in order of increasing alumina content.

\subsubsection{Randomness and chemical mixing}

Structural modification in the glass network is also reflected by the angular distribution function of triplets F-O-F' (F and F' are network formers $\mathrm{Si}, \mathrm{B}$, or $\mathrm{Al}$ ). Changes in the width of distribution can also give information on the degree of topological disorder in the network.

\subsubsection{Angular distribution}

With increasing silica content and respective decrease in boron content (See Fig.16), there is sharpening of Si-O-Si peak, broadening of Si-O-B and diminishing B-O-B, as we go from SBN-433 to SBN-955. After series of DC, broadening (confirmed by calculating FWHM, see supporting information) and slight shift to the left of distribution function can be seen, implying that there is an increase in topological disorder and decrease in mean angle. Average decrease in $\mathrm{Si}-\mathrm{O}-\mathrm{Si}, \mathrm{Si}-\mathrm{O}-\mathrm{B}$ and $\mathrm{B}-\mathrm{O}-\mathrm{B}$ was $2.41^{\circ}, 1.977^{\circ}$ and $3.28^{\circ}$ respectively and average increase in $\mathrm{O}-\mathrm{B}-\mathrm{O}$ angle by $0.78^{\circ}$ was observed. This increase is due to the formation of three coordinated $\mathrm{B}$ atoms.

For SBNA glasses (Fig.17) from SBNA-2 to SBNA-12, sharpening of Si-O-Al triplet angular distribution and diminishing intensities for $\mathrm{Si}-\mathrm{O}-\mathrm{Si}$ and $\mathrm{Si}-\mathrm{O}-\mathrm{B}$ which is in agreement with increasing alumina content. Further, after series of DC, Si-O-Si and Si-O-B can be clearly seen broadening and shifting towards left, this change is not as prominent for Si-O-Al. The mean decrease in Si-O-Si, Si-O-B, B-O-B, and Si-O-Al was $2.45^{\circ}, 1.77^{\circ}, 1.98^{\circ}$ and $1.81^{\circ}$, respectively and mean increase in $\mathrm{O}-\mathrm{B}-\mathrm{O}$ and $\mathrm{Al}-\mathrm{O}-\mathrm{Al}$ was $1.023^{\circ}$ and $2.30^{\circ}$, respectively.

Decrease in mean Si-O-Si angle has been observed in- $\mathrm{Cm}_{\text {doped }} \mathrm{ISG}^{1}$ glass [52], gold irradiated CJ1 glass [62] and other molecular dynamics simulations on borosilicate glasses $[11,28,29]$. This decrease has been associated with the increasing depolymerization and disorder (observed in previous sections), which leads to decrease in number of ring entities and broadening of ring distribution. Similar effects on Si-O-Si angle have been observed in glasses prepared at high quenching rate.

\footnotetext{
${ }^{1}$ International Simple Glass $\left[16.0 \mathrm{~B}_{2} \mathrm{O}_{3}, 12.6 \mathrm{Na}_{2} \mathrm{O}, 3.8 \mathrm{Al}_{2} \mathrm{O}_{3}, 5.7 \mathrm{CaO}, 1.7 \mathrm{ZrO}_{2}\right]$
} 


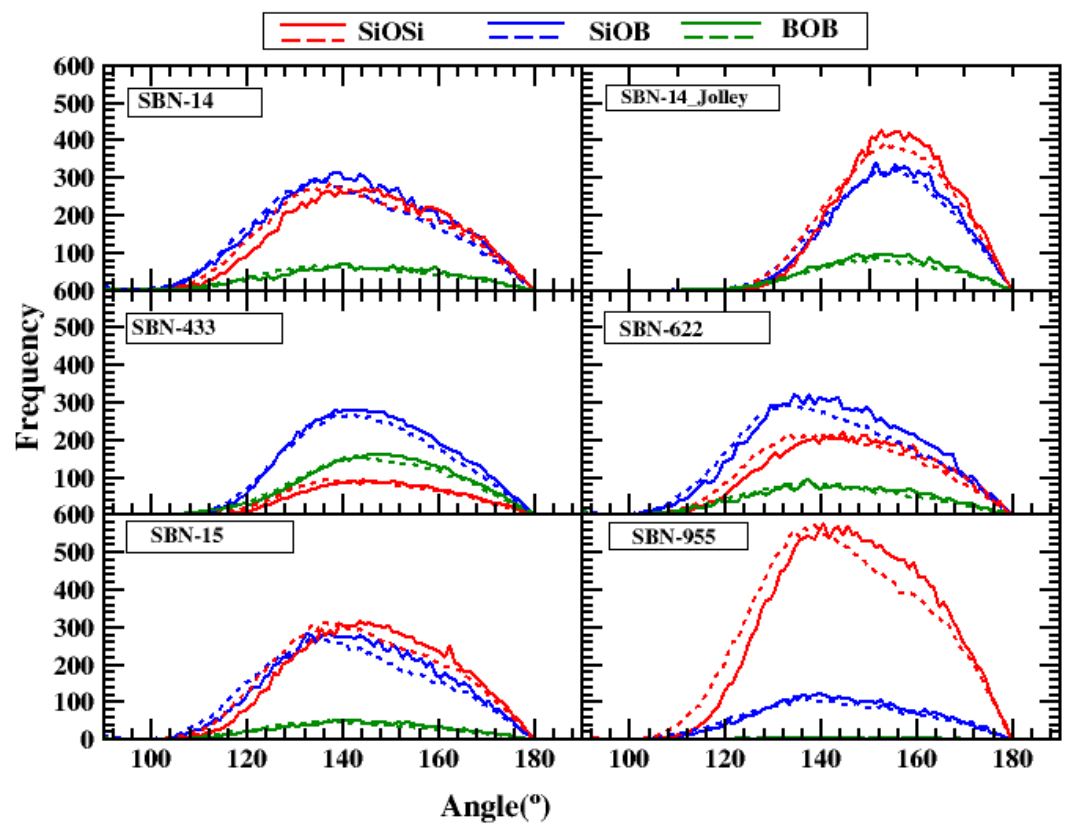

Figure 126. Angular distribution function for triplets for different SBN glasses before (solid line) and after (dotted line) series of DC

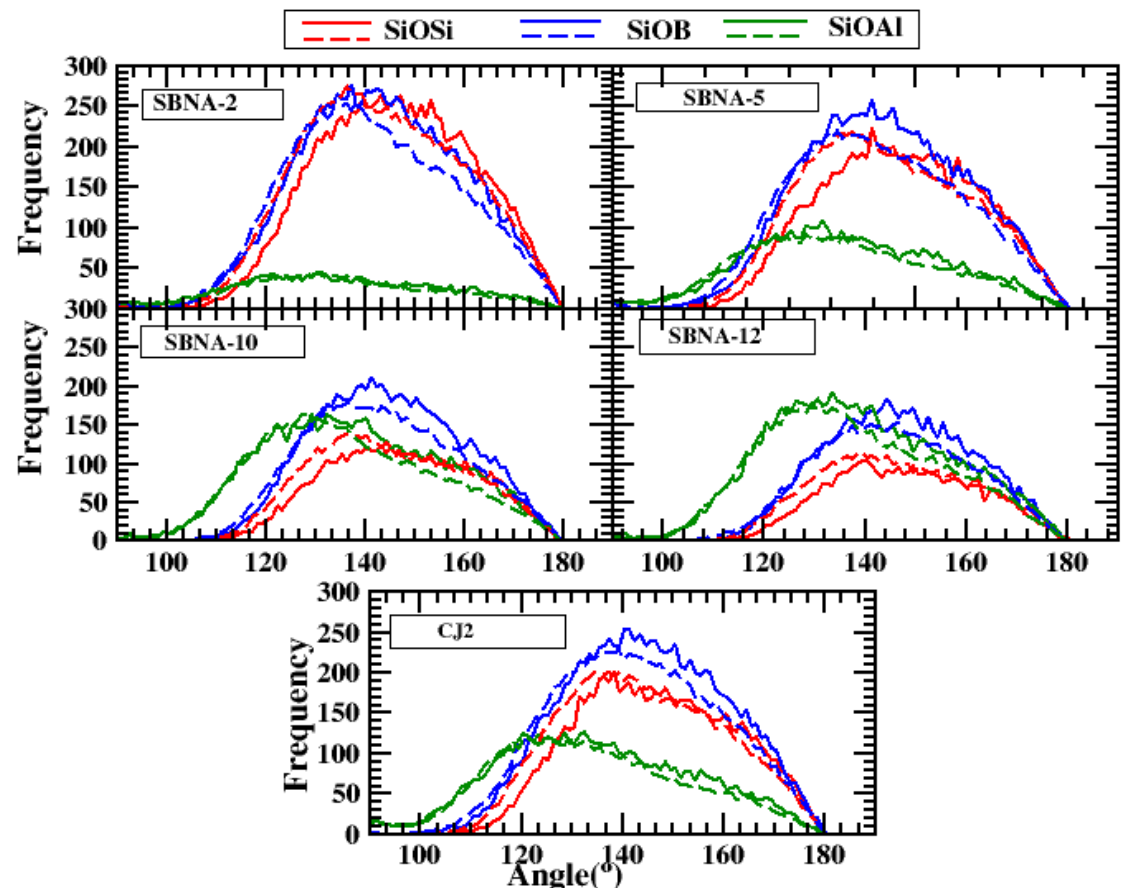

Figure 13. Angular distribution function for triplets for different SBNA glasses before (solid line) and after (dotted line) series of DC

\subsubsection{Distribution of triplets}

Following the method presented in section 2.4.2, number of triplets associated with two coordinated oxygen $\left({ }^{2} \mathrm{O}\right)$, assuming random mixing, were calculated. Comparing the shaded region between solid lines (BDC) and dotted lines (ADC) (see Fig. 18), implying an increase in random mixing even though the number of mixed triplets seems to decrease. 

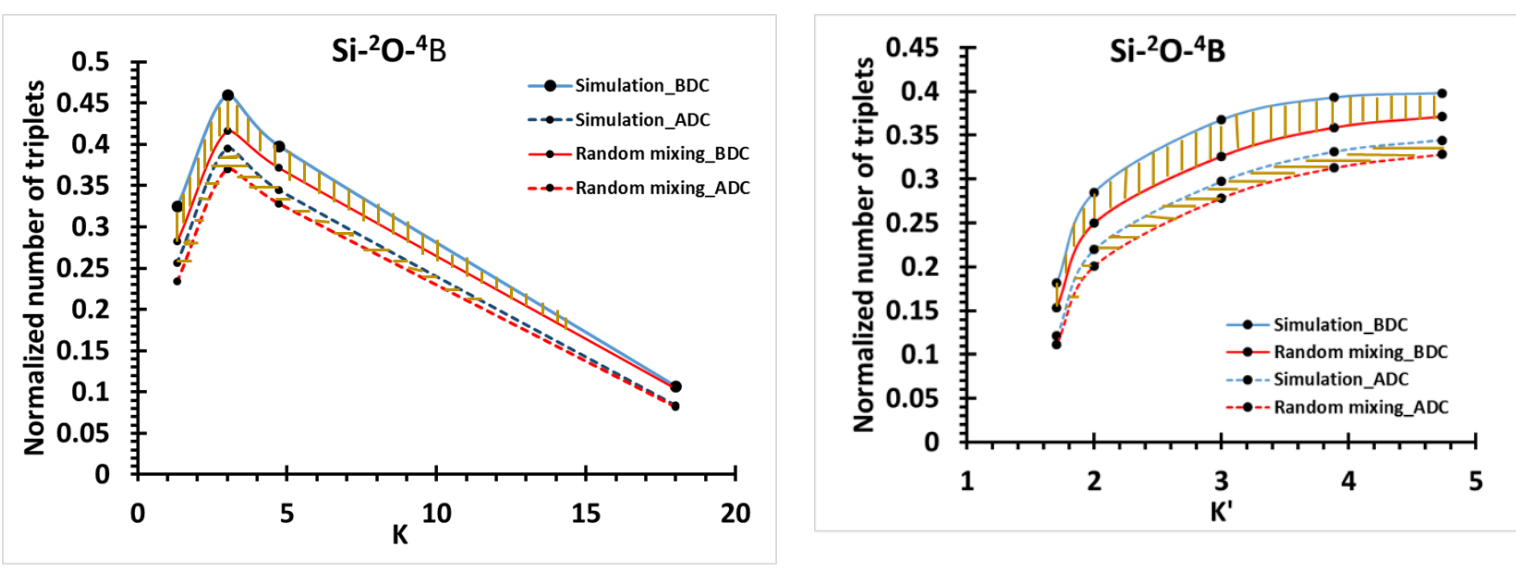

Figure 14. Comparison between number of triplets from random mixing and simulation. Distribution of triplets before (solid lines) and after (dotted lines) in SBN (left) and SBNA (Right) glasses with $K$ and $K$ ' ratio respectively. The shaded area between the solid lines is higher than area between dotted lines

\section{Discussion}

\subsection{Validity of potentials}

All the glasses studied in the current paper were prepared with the potentials proposed by Kieu and Deng for borosilicate and alumino-borosilicates, respectively. Considering the selected preparation scheme, these potentials slightly overestimate the density but the other investigated structural parameters were found to be in good agreement with experimental results. Density and coordination of SBN-955 was not correctly simulated. It should be noted that this composition lies outside the scope of Kieu's potentials[33] although other reasons such as high quenching rate and low probability of boron finding sodium for charge compensation were also cited as possible reasons for these shifts. SBN-955 was prepared with lower quenching rate $(2.5 \mathrm{~K} / \mathrm{ps})$. The estimation on density and boron coordination did not show any significant improvement, implying inability to simulate high silica content glasses may be an inherent drawback of this potential.

\subsection{Ballistic effects and role of $\mathrm{Al}_{2} \mathrm{O}_{3}$}

Even if in the scope of this study, SBNA glasses were found to be less impacted by ballistic effects compared to SBN glasses, it is interesting to notice that both in borosilicate and alumino silicate glasses, accumulation of displacement cascades lead to a new glass configuration characterized by a lower density and a larger structural disorder, i.e. increase of the width of the angular distributions and ring size distributions, increase of the chemical mixing, increase in the $\mathrm{NBO}$ and ${ }^{3} \mathrm{O}$ concentrations. These results are in agreement with experimental ones and with previous molecular dynamics studies [11,27,29,50,53,54].

The $\mathrm{Al}_{2} \mathrm{O}_{3}$ addition does not modify qualitatively the ballistic effects but their intensity is reduced. Table 3 compares various structural parameters between SBN and SBNA glasses after series of DC. Average has been taken over all SBN or SBNA glasses for each parameter. In glasses containing alumina, swelling, depolymerization and structural disordering are lower. In fact more NBOs' and ${ }^{3} \mathrm{O}$ entities are formed after irradiation in $\mathrm{SBN}$ glasses.

Fig. 19, decrease in depolymerization after irradiation when the $\mathrm{Al}_{2} \mathrm{O}_{3} / \mathrm{SiO}_{2}$ ratio increases is confirmed as less NBOs are formed around the Si and B local entities. Nevertheless the number of NBOs introduced per Al does not change significantly. 
Table 3.Comparison of structural parameters between SBN and SBNA glasses after series of $D C$, the middle column between SBN and SBNA shows relation and last column presents the trend followed after DC. Average has been taken over all glass compositions for SBN and SBNA glasses

\begin{tabular}{|c|c|c|c|c|}
\hline \multirow{2}{*}{ Parameter } & \multicolumn{4}{|c|}{ Average change with respect to initial value } \\
\hline & $S B N$ & & SBNA & Trend \\
\hline$\langle$ Density $>$ & -0.148 & $>$ & -0.128 & Decrease \\
\hline$\left\langle C_{B}\right\rangle$ & -0.112 & $<$ & -0.143 & Decrease \\
\hline$\langle\mathrm{SiOSi}\rangle$ & -2.41 & $\sim$ & -2.45 & Decrease \\
\hline$\langle\mathrm{OSiO}\rangle$ & -0.011 & $>$ & -0.003 & Decrease \\
\hline$\langle B O B\rangle$ & -3.287 & $>$ & -1.98 & Decrease \\
\hline$\langle O B O\rangle$ & +0.78 & $<$ & +1.02 & Increase \\
\hline$\langle\mathrm{SiOB}\rangle$ & -1.978 & $>$ & -1.775 & Decrease \\
\hline$\left\langle\mathrm{O}^{3} \mathrm{BO}\right\rangle$ & +0.079 & $\sim$ & +0.069 & Increase \\
\hline$\langle N B O\rangle$ & +661.39 & $>$ & $\begin{array}{r}+639.59 \\
\end{array}$ & Increase \\
\hline$\left\langle^{2} O\right\rangle$ & -802.18 & $>$ & -674.30 & Decrease \\
\hline$\left\langle^{3} O\right\rangle$ & +149.25 & $\gg$ & +34.90 & Increase \\
\hline
\end{tabular}

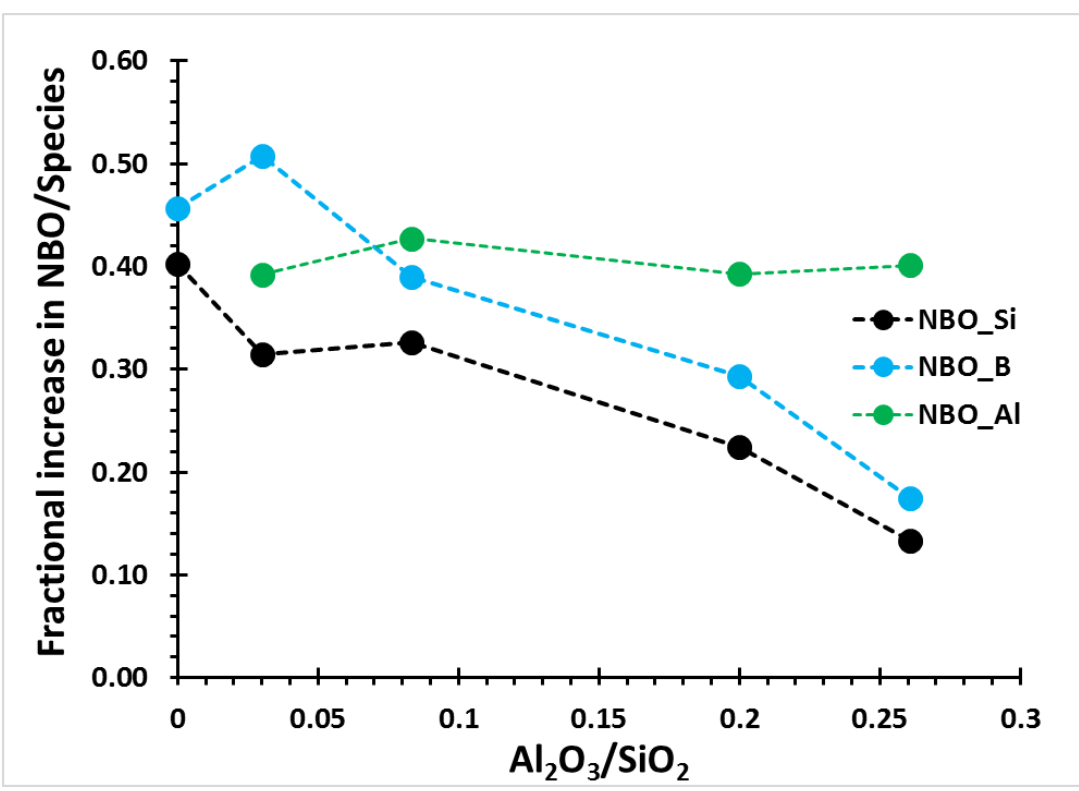

Figure 15. Fractional increase after DC, in number of $\mathrm{NBOs}$ ' per species versus alumina to silica ratio.

3.3. How displacement cascade results will be used in Monte Carlo calculations of the glass alteration

It has been marked by various studies that decrease in boron coordination and depolymerisation in glasses, may affect the reactivity of the glass towards dissolution [2,22,63-67]. Impact of other parameters such as evolution of angular and ring distribution, on dissolution of glass, are still not well understood. On the other hand, it has been widely accepted that leaching will be the most probable process of release of radionuclides from the glass, and recent experiments with irradiated glasses show an increase in leaching rate and alteration depth. In the ongoing study, effect of irradiation on glass leaching will be investigated by considering in Monte Carlo simulations, boron coordination change, 
depolymerisation, and angular and ring distribution change. This will be done first by modifying the Monte Carlo network by changing the average $\mathrm{B}$ coordination or the polymerization level, and second by playing on the different probabilities (probability for dissolution and condensation) by replacing constant values by distributions of values.

\section{Conclusions}

To study ballistic effects in $\mathrm{SiO}_{2}-\mathrm{B}_{2} \mathrm{O}_{3}-\mathrm{Na}_{2} \mathrm{O}$ and $\mathrm{SiO}_{2}-\mathrm{B}_{2} \mathrm{O}_{3}-\mathrm{Na}_{2} \mathrm{O}-\mathrm{Al}_{2} \mathrm{O}_{3}$ glasses, series of displacement cascades were simulated for a large set of compositions. Qualitatively, the borosilicate and alumino-borosilicate glasses behaved in the same way under the accumulation of displacement cascades. A swelling is systematically observed and the irradiated structures are characterized by a larger structural disorder and an increase of the chemical mixing that approaches the random chemical mixing.

Nevertheless, it has been observed that the radiation effects are attenuated after the $\mathrm{Al}_{2} \mathrm{O}_{3}$ addition. The swelling and the structural changes are lower. This can be understood as the consequence of the large strength of the $\mathrm{AlO}_{4}$ entities. During the quench after the radiation effects, these entities rebuild very rapidly and in consequence the structural changes are limited.

\section{ACKNOWLEDGMENTS}

We are grateful for the computing resources

\section{References}

[1] S. Gin, A. Abdelouas, L.J. Criscenti, W.L. Ebert, K. Ferrand, T. Geisler, M.T. Harrison, Y. Inagaki, S. Mitsui, K.T. Mueller, J.C. Marra, C.G. Pantano, E.M. Pierce, J.V. Ryan, J.M. Schofield, C.I. Steefel, J.D. Vienna, An international initiative on long-term behavior of high-level nuclear waste glass, Mater. Today. 16 (2013) 243-248. doi:10.1016/j.mattod.2013.06.008.

[2] W.J. Weber, R.C. Ewing, C.A. Angell, G.W. Arnold, A.N. Cormack, J.M. Delaye, D.L. Griscom, L.W. Hobbs, A. Navrotsky, D.L. Price, A.M. Stoneham, M.C. Weinberg, Radiation effects in glasses used for immobilization of high-level waste and plutonium disposition, J. Mater. Res. 12 (1997) 1946-1978. doi:10.1557/JMR.1997.0266.

[3] M. Tribet, S. Rolland, S. Peuget, V. Broudic, M. Magnin, T. Wiss, C. Jégou, Irradiation Impact on the Leaching Behavior of HLW Glasses, Procedia Mater. Sci. 7 (2014) 209-215. doi:10.1016/j.mspro.2014.10.027.

[4] S. Gin, Open Scientific Questions about Nuclear Glass Corrosion, Procedia Mater. Sci. 7 (2014) 163171. doi:10.1016/j.mspro.2014.10.022.

[5] J.D. Vienna, J. V. Ryan, S. Gin, Y. Inagaki, V.J. D., R.J. V., G. Stéphane, I. Yaohiro, J.D. Vienna, J. V. Ryan, S. Gin, Y. Inagaki, Current Understanding and Remaining Challenges in Modeling Long-Term Degradation of Borosilicate Nuclear Waste Glasses, Int. J. Appl. Glas. Sci. 4 (2013) 283-294. doi:10.1111/ijag.12050.

[6] C. Poinssot, S. Gin, Long-term Behavior Science: The cornerstone approach for reliably assessing the long-term performance of nuclear waste, J. Nucl. Mater. 420 (2012) 182-192.

[7] S. Gin, P. Jollivet, M. Fournier, F. Angeli, P. Frugier, T. Charpentier, Origin and consequences of silicate glass passivation by surface layers, Nat. Commun. 6 (2015) 6360.

[8] S. Gin, M. Collin, P. Jollivet, M. Fournier, Y. Minet, L. Dupuy, T. Mahadevan, S. Kerisit, J. Du, Dynamics of self-reorganization explains passivation of silicate glasses, Nat. Commun. 9 (2018) 2169. doi:10.1038/s41467-018-04511-2.

[9] J.-M. Delaye, D. Ghaleb, Dynamic processes during displacement cascades in oxide glasses: A 
molecular-dynamics study, Phys. Rev. B. 61 (2000) 14481-14494. doi:10.1103/PhysRevB.61.14481.

[10] D.A. Kilymis, J.-M. Delaye, S. Ispas, Density effects on the structure of irradiated sodium borosilicate glass: A molecular dynamics study, J. Non-Cryst. Solids. 432 (2016) 354. doi:10.1016/J.JNONCRYSOL.2015.10.031.

[11] S. Peuget, J.-M. Delaye, C. Jégou, Specific outcomes of the research on the radiation stability of the French nuclear glass towards alpha decay accumulation, J. Nucl. Mater. 444 (2014) 76-91. doi:10.1016/J.JNUCMAT.2013.09.039.

[12] S. Gin, P. Jollivet, M. Tribet, S. Peuget, S. Schuller, Radionuclides containment in nuclear glasses: An overview, Radiochim. Acta. 105 (2017) 927-959. doi:10.1515/ract-2016-2658.

[13] W.J. Weber, Radiation and Thermal Ageing of Nuclear Waste Glass, Procedia Mater. Sci. 7 (2014) 237246. doi:10.1016/J.MSPRO.2014.10.031.

[14] W.J. Weber, F.P. Roberts, A Review of Radiation Effects in Solid Nuclear Waste Forms, Nucl. Technol. 60 (1983) 178-198. doi:10.13182/NT83-A33073.

[15] S. Peuget, P.-Y. Noël, J.-L. Loubet, S. Pavan, P. Nivet, A. Chenet, Effects of deposited nuclear and electronic energy on the hardness of R7T7-type containment glass, Nucl. Instruments Methods Phys. Res. Sect. B Beam Interact. with Mater. Atoms. 246 (2006) 379-386.

[16] T. Advocat, P. Jollivet, J.. Crovisier, M. del Nero, Long-term alteration mechanisms in water for SON68 radioactive borosilicate glass, J. Nucl. Mater. 298 (2001) 55-62. doi:10.1016/S0022-3115(01)00621-3.

[17] S. Rolland, T. Magaly, J. Christophe, B. Véronique, M. Magali, P. Sylvain, W. Thierry, J. Arne, B. Antoine, T. Pierre, 99Tc- and 239Pu-Doped Glass Leaching Experiments: Residual Alteration Rate and Radionuclide Behavior, Int. J. Appl. Glas. Sci. 4 (2013) 295-306. doi:10.1111/ijag.12051.

[18] S. Peuget, V. Broudic, C. Jégou, P. Frugier, D. Roudil, X. Deschanels, H. Rabiller, P.Y. Noel, Effect of alpha radiation on the leaching behaviour of nuclear glass, J. Nucl. Mater. 362 (2007) 474-479.

[19] S. Mougnaud, M. Tribet, J.-P. Renault, P. Jollivet, G. Panczer, T. Charpentier, C. Jégou, Effect of low dose electron beam irradiation on the alteration layer formed during nuclear glass leaching, J. Nucl. Mater. 482 (2016) 53-62. doi:10.1016/J.JNUCMAT.2016.10.008.

[20] D.M. Wellman, J.P. Icenhower, W.J. Weber, Elemental dissolution study of Pu-bearing borosilicate glasses, J. Nucl. Mater. 340 (2005) 149-162. doi:10.1016/j.jnucmat.2004.10.166.

[21] X. Deschanels, S. Peuget, J.N. Cachia, T. Charpentier, Plutonium solubility and self-irradiation effects in borosilicate glass, Prog. Nucl. Energy. 49 (2007) 623-634. doi:10.1016/J.PNUCENE.2007.05.001.

[22] S. Mougnaud, M. Tribet, J.-P. Renault, S. Gin, S. Peuget, R. Podor, C. Jégou, Heavy ion radiation ageing impact on long-term glass alteration behavior, J. Nucl. Mater. 510 (2018) 168-177. doi:10.1016/J.JNUCMAT.2018.07.046.

[23] S. Kerisit, E.M. Pierce, Monte Carlo simulations of the dissolution of borosilicate glasses in nearequilibrium conditions, J. Non. Cryst. Solids. 358 (2012) 1324-1332. doi:10.1016/j.jnoncrysol.2012.03.003.

[24] F. Devreux, A. Ledieu, P. Barboux, Y. Minet, Leaching of borosilicate glasses. II. Model and MonteCarlo simulations, J. Non. Cryst. Solids. 343 (2004) 13-25.

[25] S. Kerisit, E.M. Pierce, J. V. Ryan, Monte Carlo simulations of coupled diffusion and surface reactions during the aqueous corrosion of borosilicate glasses, J. Non. Cryst. Solids. 408 (2015) 142-149.

[26] J.-M. Delaye, D. Ghaleb, Combining two types of molecular dynamics for rapid computation of highenergy displacement cascades. II. Application of the method to a 70-keV cascade in a simplified nuclear glass, Phys. Rev. B. 71 (2005) 224204. doi:10.1103/PhysRevB.71.224204.

[27] D. Kilymis, A. Faivre, T. Michel, S. Peuget, J.-M. Delaye, J. Delrieu, M. Ramonda, S. Ispas, Raman spectra of indented pristine and irradiated sodium borosilicate glasses, J. Non. Cryst. Solids. 464 (2017) 5-13. doi:10.1016/j.jnoncrysol.2017.03.012.

[28] J.-M. Delaye, S. Peuget, G. Calas, L. Galoisy, Comparative effects of thermal quenching and ballistic collisions in SiO2-B2O3-Na2O glass, Nucl. Instruments Methods Phys. Res. Sect. B Beam Interact. with Mater. Atoms. 326 (2014) 256-259. doi:10.1016/J.NIMB.2013.10.061.

[29] J.-M. Delaye, S. Peuget, G. Bureau, G. Calas, Molecular dynamics simulation of radiation damage in 
glasses, J Non-Cryst. Solids. 357 (2011) 2763.

[30] J.M. Delaye, D. Ghaleb, Volume change origin in glasses subjected to ballistic collisions: Molecular dynamics simulations, Nucl. Instruments Methods Phys. Res. Sect. B Beam Interact. with Mater. Atoms. 191 (2002) 10-16. doi:10.1016/S0168-583X(02)00505-0.

[31] E.A. Maugeri, S. Peuget, D. Staicu, A. Zappia, C. Jegou, T. Wiss, Calorimetric Study of Glass Structure Modification Induced by $\alpha$ Decay, J. Am. Ceram. Soc. 95 (2012) 2869-2875. doi:10.1111/j.15512916.2012.05304.x.

[32] W.J. Dell, P.J. Bray, S.Z. Xiao, 11B NMR studies and structural modeling of Na2O-B2O3-SiO2 glasses of high soda content, J. Non. Cryst. Solids. 58 (1983) 1-16. doi:10.1016/0022-3093(83)90097-2.

[33] L. Deng, J. Du, Development of effective empirical potentials for molecular dynamics simulations of the structures and properties of boroaluminosilicate glasses, J. Non. Cryst. Solids. 453 (2016) 177-194. doi:10.1016/J.JNONCRYSOL.2016.09.021.

[34] L.-H. Kieu, J.-M.J.-M. Delaye, L. Cormier, C. Stolz, Development of empirical potentials for sodium borosilicate glass systems, J. Non-Cryst. Solids. 357 (2011) 3313. doi:10.1016/j.jnoncrysol.2011.05.024

[35] Y.H. Yun, P.J. Bray, Nuclear magnetic resonance studies of the glasses in the system Na2O-B2O3-SiO2, J. Non-Cryst. Solids. 27 (1978) 363. doi:10.1016/0022-3093(78)90020-0.

[36] K. Jolley, R. Smith, K. Joseph, Borosilicate glass potentials for radiation damage simulations, Nucl. Instruments Methods Phys. Res. Sect. B Beam Interact. with Mater. Atoms. 352 (2015) 140-144. doi:10.1016/J.NIMB.2014.12.024.

[37] J.-M. Delaye, V. Louis-Achille, D. Ghaleb, Modeling oxide glasses with Born-Mayer-Huggins potentials: Effect of composition on structural changes, J. Non. Cryst. Solids. 210 (1997) 232-242. doi:10.1016/S0022-3093(96)00604-7.

[38] L. Cormier, D. Ghaleb, D.R. Neuville, J.-M. Delaye, G. Calas, Chemical dependence of network topology of calcium aluminosilicate glasses: a computer simulation study, J. Non. Cryst. Solids. 332 (2003) 255-270. doi:10.1016/J.JNONCRYSOL.2003.09.012.

[39] L. Huang, J. Kieffer, Thermomechanical anomalies and polyamorphism in B2O3 glass: A molecular dynamics simulation study, Phys. Rev. B. 74 (2006) 224107. doi:10.1103/PhysRevB.74.224107.

[40] L. Huang, J. Kieffer, Molecular dynamics study of cristobalite silica using a charge transfer three-body potential: Phase transformation and structural disorder, J. Chem. Phys. 118 (2003) 1487-1498. doi:10.1063/1.1529684.

[41] S. H Garofalini, H.M. Tai, U. Joelyn, Simulations of the surfaces of soda lime aluminoborosilicate glasses exposed to water, J. Am. Ceram. Soc. 101 (2017) 1135-1148. doi:10.1111/jace.15237.

[42] H. Inoue, A. Masuno, Y. Watanabe, Modeling of the Structure of Sodium Borosilicate Glasses Using Pair Potentials, J. Phys. Chem. B. 116 (2012) 12325-12331. doi:10.1021/jp3038126.

[43] A.F. Alharbi, K. Jolley, A.J. Archer, J.K. Christie, A new potential for radiation studies of borosilicate glass, Nucl. Instruments Methods Phys. Res. Sect. B Beam Interact. with Mater. Atoms. 393 (2017) 7376. doi:10.1016/j.nimb.2016.12.007.

[44] P. Stoch, A. Stoch, Structure and properties of Cs containing borosilicate glasses studied by molecular dynamics simulations, J. Non. Cryst. Solids. 411 (2015) 106-114. doi:10.1016/j.jnoncrysol.2014.12.029

[45] I.T. Todorov, W. Smith, K. Trachenko, M.T. Dove, DL POLY 3: new dimensions in molecular dynamics simulations via massive parallelism, J. Mater. Chem. 16 (2006) 1911. doi:10.1039/b517931a.

[46] E. de Leeuw ,S;Perram ,J; Smith, Simulation of electrostatic systems in periodic boundary conditions. I. Lattice sums and dielectric constants, Proc. R. Soc. London. A. Math. Phys. Sci. 373 (1980) 27 LP-56.

[47] J.F. Ziegler, M.D. Ziegler, J.P. Biersack, SRIM - The stopping and range of ions in matter (2010), Nucl. Instruments Methods Phys. Res. Sect. B Beam Interact. with Mater. Atoms. 268 (2010) 1818-1823. doi:10.1016/J.NIMB.2010.02.091.

[48] J.B. Ziegler, J.P. Biersack, U. Littmark, The Stopping Power and Ranges of Ions in Matter, 1985.

[49] J.-M. Delaye, L. Cormier, D. Ghaleb, G. Calas, Investigation of multicomponent silicate glasses by coupling WAXS and molecular dynamics, J. Non. Cryst. Solids. 293-295 (2001) 290-296. doi:10.1016/S0022-3093(01)00680-9. 
[50] D.A. Kilymis, J.-M. Delaye, Nanoindentation studies of simplified nuclear glasses using molecular dynamics, J. Non-Cryst. Solids. 401 (2014) 147.

[51] D.A. Kilymis, J.-M. Delaye, Deformation mechanisms during nanoindentation of sodium borosilicate glasses of nuclear interest, J. Chem. Phys. 141 (2014) 14504.

[52] C. Mendoza, E.A. Maugeri, J.M. Delaye, R. Caraballo, T. Charpentier, M. Tribet, O. Bouty, C. Jégou, Alpha Decays Impact on Nuclear Glass Structure, Procedia Mater. Sci. 7 (2014) 252-261. doi:10.1016/j.mspro.2014.10.033.

[53] T. Charpentier, L. Martel, A.H. Mir, J. Somers, C. Jégou, S. Peuget, Self-healing capacity of nuclear glass observed by NMR spectroscopy, Sci. Rep. 6 (2016) 25499.

[54] D.A. Kilymis, J.-M. Delaye, S. Ispas, Nanoindentation of the pristine and irradiated forms of a sodium borosilicate glass: Insights from molecular dynamics simulations, J. Chem. Phys. 145 (2016) 44505. doi:10.1063/1.4959118.

[55] M. Barlet, J.-M. Delaye, B. Boizot, D. Bonamy, R. Caraballo, S. Peuget, C.L. Rountree, From network depolymerization to stress corrosion cracking in sodium-borosilicate glasses: Effect of the chemical composition, J. Non. Cryst. Solids. 450 (2016) 174-184. doi:10.1016/j.jnoncrysol.2016.07.017.

[56] M. Barlet, A. Kerrache, J.-M. Delaye, C.L. Rountree, SiO2-Na2O-B2O3 density: A comparison of experiments, simulations, and theory, J. Non. Cryst. Solids. 382 (2013) 32-44. doi:10.1016/J.JNONCRYSOL.2013.09.022.

[57] F. Angeli, O. Villain, S. Schuller, T. Charpentier, D. de Ligny, L. Bressel, L. Wondraczek, Effect of temperature and thermal history on borosilicate glass structure, Phys. Rev. B. 85 (2012) 54110. doi:10.1103/PhysRevB.85.054110.

[58] J.F. Stebbins, S.E. Ellsworth, Temperature Effects on Structure and Dynamics in Borate and Borosilicate Liquids: High-Resolution and High-Temperature NMR Results, J. Am. Ceram. Soc. 79 (1996) 22472256. doi:10.1111/j.1151-2916.1996.tb08969.x.

[59] J. Wu, J.F. Stebbins, Quench rate and temperature effects on boron coordination in aluminoborosilicate melts, J. Non. Cryst. Solids. 356 (2010) 2097-2108. doi:10.1016/J.JNONCRYSOL.2010.08.015.

[60] J.E. Shelby, Introduction to Glass Science and Technology, Royal Society of Chemistry, UK, 2005.

[61] S. Le Roux, P. Jund, Ring statistics analysis of topological networks: New approach and application to amorphous GeS2 and SiO2 systems, Comput. Mater. Sci. 49 (2010) 70. doi:10.1016/J.COMMATSCI.2010.04.023.

[62] S. Peuget, E.A. Maugeri, T. Charpentier, C. Mendoza, M. Moskura, T. Fares, O. Bouty, C. Jégou, Comparison of radiation and quenching rate effects on the structure of a sodium borosilicate glass, J. Non-Cryst. Solids. 378 (2013) 201. doi:10.1016/j.jnoncrysol.2013.07.019.

[63] M. Ren, L. Deng, J. Du, Bulk, surface structures and properties of sodium borosilicate and boroaluminosilicate nuclear waste glasses from molecular dynamics simulations, J. Non. Cryst. Solids. 476 (2017) 87-94. doi:10.1016/j.jnoncrysol.2017.09.030.

[64] G.S. Frankel, J.D. Vienna, J. Lian, J.R. Scully, S. Gin, J. V Ryan, J. Wang, S.H. Kim, W. Windl, J. Du, A comparative review of the aqueous corrosion of glasses, crystalline ceramics, and metals, Npj Mater. Degrad. 2 (2018) 15. doi:10.1038/s41529-018-0037-2.

[65] F. Bouyer, G. Geneste, S. Ispas, W. Kob, P. Ganster, Water solubility in calcium aluminosilicate glasses investigated by first principles techniques, J. Solid State Chem. 183 (2010) 2786-2796. doi:10.1016/j.jssc.2010.08.031.

[66] G. Geneste, F. Bouyer, S. Gin, Hydrogen-sodium interdiffusion in borosilicate glasses investigated from first principles, J. Non. Cryst. Solids. 352 (2006) 3147-3152. doi:10.1016/j.jnoncrysol.2006.04.023.

[67] B.C. Bunker, G.W. Arnold, D.E. Day, P.J. Bray, The effect of molecular structure on borosilicate glass leaching, J. Non. Cryst. Solids. 87 (1986) 226-253. doi:10.1016/S0022-3093(86)80080-1. 